\title{
Review \\ Thermodynamics and Inflammation: Insights into Quantum Biology and Ageing
}

\author{
Alistair Victor William Nunn ${ }^{1, *}$, Geoffrey William Guy ${ }^{2}$ and Jimmy David Bell ${ }^{1}$ (I) \\ 1 Research Centre for Optimal Health, Department of Life Sciences, University of Westminster, \\ London W1W 6UW, UK; j.bell@westminster.ac.uk \\ 2 The Guy Foundation, Dorset DT8 3HY, UK; gwg@theguyfoundation.org \\ * Correspondence: a.nunn@westminster.ac.uk
}

Citation: Nunn, A.V.W.; Guy, G.W.; Bell, J.D. Thermodynamics and Inflammation: Insights into Quantum Biology and Ageing. Quantum Rep. 2022, 4, 47-74. https://doi.org/ 10.3390/quantum4010005

Academic Editor: Michel Planat

Received: 9 November 2021

Accepted: 1 February 2022

Published: 3 February 2022

Publisher's Note: MDPI stays neutral with regard to jurisdictional claims in published maps and institutional affiliations.

Copyright: (c) 2022 by the authors. Licensee MDPI, Basel, Switzerland. This article is an open access article distributed under the terms and conditions of the Creative Commons Attribution (CC BY) license (https:// creativecommons.org/licenses/by/ $4.0 /)$.

\begin{abstract}
Inflammation as a biological concept has been around a long time and derives from the Latin "to set on fire" and refers to the redness and heat, and usually swelling, which accompanies injury and infection. Chronic inflammation is also associated with ageing and is described by the term "inflammaging". Likewise, the biological concept of hormesis, in the guise of what "does not kill you, makes you stronger", has long been recognized, but in contrast, seems to have anti-inflammatory and age-slowing characteristics. As both phenomena act to restore homeostasis, they may share some common underlying principles. Thermodynamics describes the relationship between heat and energy, but is also intimately related to quantum mechanics. Life can be viewed as a series of self-renewing dissipative structures existing far from equilibrium as vortexes of "negentropy" that ages and dies; but, through reproduction and speciation, new robust structures are created, enabling life to adapt and continue in response to ever changing environments. In short, life can be viewed as a natural consequence of thermodynamics to dissipate energy to restore equilibrium; each component of this system is replaceable. However, at the molecular level, there is perhaps a deeper question: is life dependent on, or has it enhanced, quantum effects in space and time beyond those normally expected at the atomistic scale and temperatures that life operates at? There is some evidence it has. Certainly, the dissipative adaptive mechanism described by thermodynamics is now being extended into the quantum realm. Fascinating though this topic is, does exploring the relationship between quantum mechanics, thermodynamics, and biology give us a greater insight into ageing and, thus, medicine? It could be said that hormesis and inflammation are expressions of thermodynamic and quantum principles that control ageing via natural selection that could operate at all scales of life. Inflammation could be viewed as a mechanism to remove inefficient systems in response to stress to enable rebuilding of more functional dissipative structures, and hormesis as the process describing the ability to adapt; underlying this is the manipulation of fundamental quantum principles. Defining what "quantum biological normality" is has been a long-term problem, but perhaps we do not need to, as it is simply an expression of one end of the normal quantum mechanical spectrum, implying that biology could inform us as to how we can define the quantum world.
\end{abstract}

Keywords: quantum biology; thermodynamics; ageing; inflammation; mitochondria; hormesis

\section{Introduction}

"The goal of inflammation, whether as part of the innate or acquired immune response, is the destruction of the damaging agent." Cone, 2001 [1]

The term "inflammation" literally means setting on fire, but the link between redness, heat, and damage to the body with swelling and pain has been made for millennia-but was probably first described by Celsius in the first century AD. A few centuries later, Galen added the further clinical observation-loss of function. It was not until Hunt in the 1700 s that it was realized that not only was inflammation a reaction to damage, but also a 
mechanism to defend against further injury. Today, it is known to be a highly complex and a normally well-orchestrated process, which involves many systems-including the brain. Its presence is not just indicated by the symptoms first catalogued by Celsius, but also by other more general symptoms, such as fever, lethargy, and loss of appetite-suggesting intimate involvement of the central nervous system. It should be self-limiting as once it is activated, anti-inflammatory systems are initiated, leading to its resolution, which, if the tissue is rebuilt or the infection repelled, means that homeostasis is restored. It has been said that inflammation has evolved to protect the organism, although if misdirected or too excessive, it can be extremely damaging - causing the so-called "friendly fire" outcome which leads to organ damage and, on occasion, loss of life [1].

As an apparent counter-point to inflammation, there is another concept and biological epiphenomena that has also been long described, but is only given a name in more recent times, i.e., "hormesis" [2]. This basically describes how life responds to stress: when the stress is not too severe, an organism can over-compensate adaptive mechanisms to better resist the stress next time. Too much stress and the system "fails". Critically, "hormetic" stimuli that lead to enhanced robustness tend to be anti-inflammatory [3] and have long been known to enhance longevity, shifting Gompertz mortality plots down and rightwards [4]. This would support the observation that ageing is plastic [5]. Certainly in eukaryotes, mitochondria are key in hormesis, giving rise to the term "mitohormesis", with the hormetic process being linked, for instance, to modulation of the sirtuin family [6] - which are not only well known for their involvement in controlling ageing, but in antioxidant and redox signaling as nicotinamide adenine dinucleotide (NAD)-dependent histone deacetylases [7].

A key factor than can slow the ageing process, which suppresses inflammation and upregulates mitochondrial function, autophagy, and sirtuin activity, is calorie restriction (CR) and a variety of CR mimetic drugs [8]. This indicates that ageing may be tightly linked into the availability of energy and redox because $\mathrm{NAD}(\mathrm{P}) \mathrm{H}$ is a key part of electron transfer network. Critically, compounds such as NAD(P)H were probably around since life began and are fluorescent-in effect, they can absorb light and dissipate energy, both as photons and electrons; this might suggest why biological systems, including the sirtuins, may have evolved to enhance the control of this process [9]. It can, therefore, be said that inflammation is effectively a hormetic stimulus, and, thus, it can be argued that inflammation and hormesis are part of the same allostatic system to repair, resolve, and maintain resilience. This is perhaps best described by the role that the redox-activated anti-oxidant transcription factor, nuclear factor erythroid 2-related factor 2 (Nrf2), plays in suppressing inflammation as well as enhancing longevity via hormesis [3].

For the individual human inflammatory tone tends to rise with age [10,11], indicating that "friendly fire" becomes more unfriendly as we get older. The "double-agent" theory suggests that the age-related increase in inflammatory tone is generated by oxidative stress as mitochondrial function declines-something that cannot be prevented by anti-oxidants as there is a trade-off due to the importance of redox signaling in relation to the stress response [10]. Other theories suggest that "inflammaging" actually represents an adaptive response by the immune system to maintain function as an organism ages, leading to a pro-inflammatory state but immune paralysis [12]. It has also been long observed that inflammation can repurpose mitochondria to generate reactive oxygen species (ROS) as part of the immune response [13] and is now generally accepted that they are pivotal in immunity [14]. These ideas certainly conform, to some degree, with updated versions of the free radical theory of ageing [15]. This would, therefore, suggest that, as an organism ages, its ability to mount a hormetic response decreases, leading to a left shift of the hormetic curve, but the process of hormesis itself, can, to some degree, keep the curve right shifted for longer, keeping the organism more robust and, thus, slowing down the ageing process. Ageing is clearly modulated by increasing "hormetic inflexibility". 
There are of course alternative ways to view ageing, one of which involves the degradation of a far-from-equilibrium dissipative negentropic structure. In short, life is the result of a thermodynamic and is imperative to dissipate an energy gradient, thus restoring equilibrium. Death occurs when the system degrades as its capacity to generate free energy decreases beyond a certain point and is caused by stochastic stresses and damage. The cell can, of course, self-correct to some degree, but too much overwhelms the corrective system, leading to a new state, which is associated with increased internal errors and lower internal entropy production. Overcoming stress, thus, requires energy, which can then lead to it being drawn from other systems. At the larger scale, whole ecosystems evolve complexity to increase dissipation of energy and end up in a dynamic quasi-stable state, but when stressed, they revert to a simpler system and follow the path of non-equilibrium systems. As suggested by Bortz, "ageing is entropy" [16]. These ideas are based on those developed by Prigogine which, in turn, were developed from thermodynamics as a discipline that emerged out of the science of understanding how steam engines worked [17]. Indeed, even Schrödinger in his book "What is life" discussed a thermodynamic interpretation of life [18].

It could, therefore, be said that one metric of ageing is the capacity of an organism per unit of time and mass to generate entropy, in effect, of specific entropy production (SEP). Growth occurs when more of the same type of pathways are added, and development when additional types of pathways emerge. Evolution, thus, led to ever greater complexity of metabolic pathways to achieve this. This has led to thermodynamic concepts supporting the disposable soma theory ageing, which basically stipulates that organisms must balance fecundity with maintenance of the soma. As life became more complex and moved further away from equilibrium, new systems emerged that could improve maintenance and longevity, while increasing SEP. Thus, some species evolved with better stress resistance but reduced reproductive rates, while others did the opposite according to the needs to adapt to a particular niche. Within this lies the concept of hormesis: very low levels of stress do not activate repair systems, and so accumulate damage, leading to a new steady, but less efficient state. However, moderate stress can activate these systems, and, thus, almost invoke full repair, while slightly more stress activates death programs (e.g., apoptosis), and too much leads to necrosis. These scenarios can also be approached from the theory of "attractors". For instance, at critical points in an environmental gradient, attractors shift in phase space, so the system abruptly jumps to a new response level. Critically, the outcome not only depends on the dose and temporality of the stressor, but the availability of free energy and the efficiency of the repair system [19]. Another way of viewing this is that as entropy, which is a measure of randomness, could indicate that "tailored randomness" could be a means of improving health, as it could restore biological complexity, something that is lost as ageing occurs [20]. In essence, randomness could be viewed as a form of stress and, thus, hormesis. Therefore, there is probably a sweet spot of randomness as too much induces death but too little does not induce adaptation via natural selection of individual molecules, organelles, cells, or whole biological structures

The same underlying thermodynamic principles have also been used to describe more conventionally termed biological terms, such the general adaptation syndrome, homeostasis, and allostasis. In effect, homeostasis enables the restoration of the original attractor, whereas allostasis is a chaotic search for a new attractor, and static behavior is a system effectively abandoned at a new attractor-an "allostatic crash". Obesity can lead to the latter state and the permanent activation of the inflammatory system [21]. It would, therefore, appear that as exercise is well known to improve functional health in obesity, hormesis can induce an attractor "reset", resulting in the upregulation of repair systems. However, there is perhaps a much deeper implication here: as thermodynamics describes fundamental laws about how and why energy is dissipated to restore equilibrium, it could 
be said that in high energy environments, for example, when there is plenty of food, enhanced replication and dissipation are associated with a greater turnover and shorter life of individual components-as this essentially fulfils entropy. The converse is, therefore, true: with less energy, individual components will survive longer, which might underlie CR. Perhaps a good example of this is the relationship between mitochondria, mitophagy, and the lysosomal system - which has led to the so called mitochondrial-lysosomal theory of ageing. The removal and degradation of damaged mitochondria represent essential parts of cell life, as they can result in a lot of oxidative stress. However, they are also key in providing the energy for the lysosomal system to function, which not only removes broken mitochondria, but also many other damaged components of the cell. Ageing could result in a gradual reduction in energy production, leading to a vicious cycle due to garbage build up in the cell [22].

Hence, life can also be viewed from a thermodynamic point of view, with a fundamental relationship between stress, energy, entropy, structure, and self-organization. Certainly, for modern life, this is why maintaining efficient mitochondrial function is so important in longevity - a healthy energy system can support maintenance. However, inflammation is a very energy-hungry process as it must repel pathogens, remove defective cells, and engender regeneration-all of which puts a significant load on mitochondrial function. Unfortunately, for both humans and their associates, a sedentary lifestyle removes both the hormetic stimulus for mitochondrial regeneration and growth and replaces it with a never ending drive to store excessive calories resulting in chronic inflammation and accelerated ageing [23]. This can be viewed as the "allostatic crash" mentioned above as without the hormesis, the system is perhaps not induced to jump to a new state to correct itself.

The second and perhaps less discussed way of viewing ageing is that the loss of structure leads to a reduced ability to maintain significant quantum effects, such as tunnelling-a process that hormesis might maintain, for instance, in the mitochondrion [24]. The role of quantum effects in biology has long been discussed ever since quantum mechanics was developed, but there are still debates around how to define "quantum biology" given that all chemistry, at the atomistic level, is best described by quantum mechanics-so of course, in one sense, biology is based on quantum mechanics at the smallest scales of time and space. Thus, the question then becomes centered around whether biology has harnessed and enhanced non-trivial quantum effects, such as long-lived coherence [25]. Another aspect of this, which could of course be related, is that the self-organization described by thermodynamics, which can also be called "dissipative adaption", actually embraces the quantum realm, leading to the term "quantum dissipative adaption". In effect, we are actually moving towards a quantum thermodynamics of driven self-organization [26]. This, of course, raises the rather interesting point that thermodynamics may describe what life is and how it arose, but does not indicate if it requires harnessing and amplifying quantum effects to be "alive".

In this paper, we explore the relationship between inflammation, hormesis, and ageing, as well as thermodynamics and quantum physics, and propose that inflammation and hormesis echo the oldest of adaptive solutions, including the idea that induced loss of a higher order structure can enable plastic rebuilding via natural selection under duress, and that this may require maintenance of "amplified" quantum effects which echoes the beginnings of life as a self-organizing dissipative structure. The implications are profound, as it means that we may have to view life in its entirety as a networked system where individual components are largely dispensable. From the other end of the scale, it could simply represent how the environment manipulates quantum effects to control electron flow to maintain dissipating structures. Anything that disrupts the flow of electrons towards an appropriate electron acceptor via a managed electron transport chain (ETC), for instance, 
oxygen, can result in free radicals and/or ROS, which is a powerful signal to adapt or die. Thus, inflammation and hormesis are inextricably linked, and could represent mechanisms derived from order out of chaos and the laws of thermodynamics that could well be reliant on modulating significant quantum principles, such as coherence, tunnelling, and spin. How we "categorise" them will, thus, depend on scale, how we view ageing, and, ultimately, how we approach medicine in the future. It also suggests that dissipation should be part of how we define life, and life itself could help us understand what "normal" quantum processes are.

Quantum biology, as a separate field of science, could, thus, be described as the application of quantum mechanical theory to help explain life and its complexity. For instance, processes that should normally be explainable by classical mechanisms but cannot, pointing to non-trivial quantum processes, are of fundamental importance [27]. The link to ageing and inflammation concerns space and time hierarchy, with "classical" higher order biological processes simply obeying potentially lower order non-trivial quantum processes.

\section{Thermodynamics and Inflammation}

The application of thermodynamics to life is now well established, as it seems able, on several levels, to describe it and its origins using dissipative systems theories, especially those of Prigogine $[17,28,29]$. From this angle, it seems that replication is a key mechanism that ensures that functional dissipating structures replace ones that fail. It is likely that life, ageing, and death are shaped by thermodynamics and a consensus emerging on the possibility that life is inevitable due to the fundamental nature of the Universe. This had led to mathematical models being developed that indicate that self-replication is driven by entropy [30]. According to thermodynamics and order-chaos theories, stress results in predictable changes in a network can help explore phase space for more efficient attractors, enabling adaptation to ensure entropy [31]. Hence, how we view life depends on scale, and is tightly linked to the ageing process inflammation, hormesis, and the longevity of many species-and it is all driven by fundamental principles, as laid out in thermodynamic theories, to equilibrate energy differences. Thus, in this regard, inflammation is simply a term describing how a thermodynamic system attempts to restore itself by resorting to simpler dissipative structures before rebuilding to something more complex.

\subsection{Energy Driven Replication}

A key component of dissipative theories is the ability to dissipate energy. It is thought that the thermodynamically driven self-organizing ability of lipids to form micelles is based on basic physical properties that may underlie cell structure and life. Cells can be viewed as self-organizing dissipative structures that need a border, energy inflow, and entropy outflow [28]. In effect, cells exist far from thermodynamic equilibrium, but exist as thermodynamically semi-open systems by using energy to create internal order. However, the larger they become, the more difficult it is to maintain this order. Moreover, the basic physical properties of fatty acid membranes and energy distribution set an upper limit to surface-volume ratios; the energy issue was overcome in eukaryotes by mitochondria, but other thermodynamic limits remain $[30,32,33]$. When put together with the self-organizing properties of matter and the emergence of dissipative metabolic networks, and the importance of information processing, then it becomes possible to understand how enzyme-based networks gave rise to more complex cellular lifeforms [34]. A key point, however, is that not all structures are dissipative, although they can spontaneously form - but they may well be essential for life, such as membranes. Aside from these self-assembly structures, there are several types of true dissipative structures: those involving multi-stability, temporary 
dissipative structures involving sustained oscillations, temporal dissipative structures (Turing patterns), and spatio-temporal structures involving wave propagation. In fact, many biological rhythms are examples of dissipation [35]. The key point here is that an energy potential can, under some circumstances, drive the formation of structures that accelerate entropy, and because replication is a way of enhancing energy dissipation, this is one way to view why life constantly replicates and expands when driven by large energy gradients.

\subsection{A Fresh Look at Inflammation-A Question of Scale}

The term "inflammation" was assigned at a time when the underlying science was hardly understood [1]. Today, with a greater understanding, it may be possible to take a fresh look at what "inflammation" actually is. For example, if life can be viewed as a dissipative structure, driven by entropy and the natural laws governing order out of chaos under perturbation, then, as described by Le Chatelier's network principle [31], the entire process of inflammation and resolution could represent the re-establishment of a network following disruption. Critically, inflammation can also induce disruption of smaller networks to ensure functioning of larger ones. This might suggest that breaking up a network/higher order structure is essential to enable rebuilding and, thus, we cannot simply view inflammation at the level of the individual organism, but at the level of populations or even collections of populations. One explanation is that life on earth can be viewed as a "fourth geosphere", as, in effect, it is a kind of emergent property of the planet. Hence, individual species come and go, but life itself remains stable over immense periods of time because, at a global level, it adapts [36]. This is clearly reflected in how self-organization and information in basic enzyme networks form dissipative metabolic networks (DMN) and are also reflected at larger scales, such as cells and whole organisms, and by the ability to learn [34].

\subsection{Inflammation, Morphogenetic Fields, and the Cycle of Brillouin}

An important function of inflammation is repair, which suggests that the process requires information about the prior state. Interestingly, it is now thought that some of the information about how to regenerate a tissue after damage is held in its "morphogenetic" electric field. This begins to explain how small numbers of cells, acting together, can maintain a collective memory field that is synergistically greater than any single cell, even though they all contain the same genes [37]. It is, thus, relevant that it has been suggested that life is a self-organizing machine driven by the informational cycle of Brillouin. This essentially states that the successful replicating unit incorporates information about the environment, which even though it has an energy penalty, it has a selective advantage through positive feedback. Life, therefore, has over billions of cycles, as well as incorporated information which enables it to reach ever higher complexity and robustness. This is entirely in keeping with the very tight relationship between thermodynamics and information theory [38]. Putting this together with the morphogenetic field concept may indicate how complex cell communities can cooperate and repair, which has perhaps provided them with an advantage in terms of fitness.

Cooperativity is, of course, a well described biological concept in large complex animals, but is also perhaps best illustrated by the social amoeba, Dictyostelium discoideum, which forms cooperative colonies under stress. Critically, it also seems to develop sentinel cells that seem to have innate immune defense qualities that predate the emergence specialist immune cells in metazoans [39]. However, this cooperation may go back much deeper in time to epochs when prokaryotes dominated the world; it seems that cooperation was the order of the day-and still is. For example, there is evidence that the ontogeny of 
growing bacterial biofilms recapitulates phylogeny-in effect, displaying embryo-like transcriptional programs more akin to that observed in multicellular eukaryotes [40]. Indeed, it has been suggested that developmental bioelectricity can drive multicellularity and scale-free cognition, and perhaps identify and define what is an individual, but also indicate that, on multiple levels, the biosphere is a series of "nested" systems. Bacteria, and their ancestors, have all the ion channels that modern "more complex" life uses for sensing the environment and as biofilms, showing complex behavior. In effect, the computational strategies that enabled survival evolved long before eukaryotes did; hence, the later evolution of complexity just built on what was already there [41].

This, therefore, suggests that inflammation is a temporary and plastic state that should self-resolve according to the informational cycle of Brillouin. In particular, if energy is limited, this will naturally select the most efficient means of energy production, via mitochondrial oxidative phosphorylation (at least in multicellular organisms) and the stabilization of informational structures, such as the brain, to ensure survival. However, a brain, as we know it, may not even be required-the simple cooperation between several cells is perhaps enough. At a species level, having plenty of energy allows rapid reproduction and would not select for longevity of the individual, but the opposite would occur in times of energy restriction. An important concept, as discussed previously, is that as cells grow, they become slightly less ordered, so splitting into two smaller cells increases their order (in effect, with plenty of energy, thermodynamics will drive the rapid multiplication of cells) [32]. However, with less energy, different survival choices must be made, which is discussed in the section on calorie restriction.

Nevertheless, why did cells cooperate in the first place? This can perhaps be explained by thermodynamics again, as touched upon in a previous section, and which we will elaborate on in the following section on the origins of life. Simply put, if the underlying principle indicates that life is an area of negative entropy dissipating energy, then individual structures would have little need to cooperate if there was unlimited energy or space, but if energy and/or space became limited, then cooperation may favor the survival of the more adaptive units-especially if the conditions kept changing. In effect, natural selection.

\section{Ageing, Immunity, and Death}

The thermodynamic principles discussed indicated that ageing and death are fundamental components of all life, but also, perhaps, so is immunity-and are ancient. One way to look at this is that pathogens, as well as cancer cells, can be highly disruptive, so recognizing these and removing them is essential. It is also essential to understand the electron and how this fundamental particle is "organised" by the laws of thermodynamics. For example, a "trigger" for inflammation could be a disrupted flow of electrons that is a symptom of a failing dissipative system, for instance, old age, or it could be triggered by some outside influence, as inflammation and immunity are very closely allied and generally act to restore homeostasis. In more modern organisms, excessive inflammation can suppress reproduction and reduce fertility $[42,43]$.

In some respects, this could be viewed as a mechanism to prevent one damaged system reproducing itself until it has repaired. One example of this could be that all modern eukaryotic cells seem to be the result of a symbiosis between a bacterium and an Archaean; thus, their respective genomes have had to work together. Mito-nuclear matching could, therefore, be key to producing functional mitochondria with minimal ROS and may have driven the evolution of fitness and fertility, and indeed, ageing and the two sexes [44]. In effect, there is a relationship between mitochondrial efficiency, inflammation, longevity, reproduction, and the maintenance of dissipative structures. What this might suggest is that inflammation can be viewed as a marker of altered electron flow through the ETC, whether it is a result of poor mitochondrial-nuclear matching or a deliberate switching of mitochondrial function in response to infection and injury. In either case, inflammation seems to suppress reproduction. 
It, therefore, seems that electron flow and, potentially, tunnelling and coherence can have a big effect on adaptation in eukaryotes, especially in the mitochondrion. Thus, clearly, a damaged mitochondrion can send a powerful signal. However, during inflammation, mitochondria can also be forced to generate a signal, suggesting the process has been adopted for signaling use in multicellular organisms. In this regard, it is perhaps relevant that the innate immune system can also transmit stress signals from cellular damage, in particular, transient DNA damage that effectively preconditions the rest of the organism; this suggests that the degree and nature of inflammatory activation is key [45]. Critically, prokaryotes also display dose-related biphasic effects to ROS, for instance, when generated by ionizing radiation [46], suggesting that the process is very old.

\subsection{Redox Perturbation Key—Follow the Electron}

As Szent-Györgyi once said, "life is nothing but an electron looking for a place to rest" [47]. However, electrons and the use of electron acceptors, in particular, oxygen, comes at a price. The same system can very quickly generate excessive free radicals if the ETC becomes too reduced, for instance, during hypoxia—or potentially, if overloaded. Hence, the evolution of mechanisms to generate energy by using alternative electron acceptors occurs during glycolysis fermentation. It is, thus, thought that glycolysis may have been a later evolutionary step in environments with very low oxygen [48]; although, there is still debate around this [49].

In modern multicellular organisms, this system is epitomized by the transcription factor, hypoxia inducible factor (HIF), which becomes active in any condition where either oxygen levels are compromised, such as during injury, or cancer, and/or there is a great demand, such as during inflammation or cell proliferation. Its fundamental role is to increase glycolysis, providing an alternative energy source, while down-regulating some aspects of mitochondrial function by increasing mitophagy and suppressing biogenesis. It also reduces lipid flow into mitochondria and increases fatty acid and nucleotide synthesis, possibly encouraging the storage of fat. It then sets in motion processes such as angiogenesis to restore the flow of oxygen [50].

One of the observations that could be derived from the above is that the efficiency of the ETC is key; if it is defective, it is more likely to generate ROS-and this could be a pivotal break through a signal for natural selection. Certainly, a healthy mitochondrion appears more able to manage its innate anti-oxidant systems by generating NADPH from electrons from the Kreb's cycle [51]. Hence, not only might a healthy mitochondrion readily manage its production ROS, but it could also neutralize any that it does. In fact, it is becoming apparent that mitochondria can actually act as net sinks of ROS [52,53], and that they have evolved to minimize ROS production when respiratory rates reach a maximum [51].

In effect, a healthy ETC tends to favor life, while a failing one indicates a lack of energy extraction and a crumbling structure. It might be surmised that increased ROS and decreasing energy have become inextricably linked throughout evolution as a marker for fitness and natural selection. Given that the ability to store information is a pivotal event in evolution, it is likely that encoding a system that broadcasts fitness signals based on ETC efficiency would have evolved. In effect, death programs would have become hard-wired as they gave a selective advantage. This process, potentially, could be linked to ageing.

\subsection{Death from the "Get Go"}

Mathematical models of spatial systems have now suggested that programmed death of an organism could be favored by natural selection, as it ensures long-term stability of resources for the species [54]. In fact, this concept of programmed death of an organism is not new and was first suggested by Weismann in 1889, and following the discovery of apoptosis, it was given a name, "phenoptosis" by Skulachev. In effect, just as mitoptosis 
of mitochondria could lead to apoptosis of the cell, wholesale loss of cells could cause organ failure and, ultimately, death of the organism-the most dramatic example of this being septic shock [55]. Although less than a million people in the USA, and about the same amount in Europe, develop sepsis, it is fatal in up to $50 \%$ of cases. Critically, in many sepsis patients, there is a severe loss of mitochondrial content in muscle-perhaps as high as $30-40 \%$ [56].

Although programmed cell death (PCD) was properly first described in the 19th century [57], it was only given a name, apoptosis, and became mainstream following the publication of the seminal paper by Kerr, Wyllie, and Currie in 1972 [58]. However, it turns out that apoptosis is far older than previously thought-and first arose in prokaryotes [59]. Prokaryotic life displays immense complexity, including between species cooperation and transfer of electrons [60], and critically cell death [59]. Thus, it has been proposed that PCD has been conserved from bacteria into modern multicellular life [61]. Hence, these characteristics are now replicated in eukaryotes as they appear to have evolved from a symbiosis between archaea and bacteria, with the bacterium becoming the mitochondrion [33]. Interestingly, new data suggest bacteria employ quorum-sensing molecules to poison the ETC chain to generate ROS; the cells then lyse and release DNA that enhances biofilm formation and resistance to antibiotics [62]. In short, some bacteria die for the greater good of the colony; critically, this mechanism involves redirection of electrons.

As expected, PCD also exists in single celled eukaryotes, which under starvation, form cooperative communities (so not unlike prokaryotes). Again, Dictyostelium discoideum acts as an example; it can form cooperative slugs that eventually produce spores under stress, but for this to occur, cells within the stalk seem to die by a kind of autophagic cell death [63]. This is key, as it suggests that when calories are limited, cooperation can help survival of the species, but to do so, some cells must die, while differentiation is induced in the survivors. So, in this respect, the concept embodied by inflammation of death and regeneration (rebuilding) is entirely in keeping with our prokaryotic ancestors. However, it is also entirely in keeping with thermodynamic dissipative principles that life is based on.

\subsection{Ageing and Immunity Are a Long-Term Partnership}

While death is ancient, the process leading up to it, if it is not violently induced, must also be so. Ageing leads to death and seems to be linked to immunity and can be viewed at different scales from the "death" of a single protein to that of an entire species. At the molecular level, having the energy and systems to ensure correct functioning of proteins is key in limiting the ageing process, which involves both good fidelity and removal of non-functional units.

There are several theories on ageing, with the three strongest adopting an evolutionary perspective that most organisms inevitably die due to predation, accident, and diseases, or exceptional harsh environmental changes. This implies that natural selection will have a reduced effect when the organism is older, especially if it has bred, and is embraced by the mutation accumulation (MA), the antagonistic pleiotropy (AP), and the disposal soma (DS) theories. Critically, the AP and DS theories predict a trade-off between ageing and fecundity. What these theories, however, have not embraced is a more subtle effect of how other species, such as viruses and bacteria, can modulate the aging processes of their host species for their own ends, i.e., the so-called "age distorter" theory. With this, viruses, in particular, can both speed up and slow down the ageing process, which may also have different effects depending on the host's age. Although it is generally thought that ageing is non-adaptive, this "age-distorer" theory could be viewed as being beneficial for non-kin species [64]. Hence, ageing theories should be viewed at a collective scale of life, as each species, whether large or small, long-lived or short-lived, modulate the longevity of other species around it. Again, from the perspective life being a dissipative structure, described via thermodynamics, this makes sense. Pathogens can potentially disrupt a functioning system. 
It could, therefore, be said that the thermodynamic theory involving dissipation and order out of chaos would suggest that ageing was imperative from the time that life started. It now seems that the DS could also apply to prokaryotes, which supports this. For example, it now seems that due to unequal division, the separation of germen and soma also occurs in prokaryotes, with one daughter cell being effectively rejuvenated, while the other suffers from physiological and/or replicative ageing. One of the possible drivers for this could be that, with DNA replication, one strand will be freshly created, while the old strand will contain epigenetic markers-in effect, DNA replication is inherently asymmetric. Thus, as was originally thought, prokaryotes are not immortal [65].

There is, thus, an interesting interplay with the evolution of ageing in prokaryotes, and then through time and evolution to eukaryotes, with each still interacting with the other. This is perhaps ably demonstrated by how the gut microbiome can alter the ageing rate in many more complex organisms, with perhaps the most surprising finding that the removal of all commensal prokaryotes via antibiotics can increase the lifespan of fruit flies, which is not associated with many of the conventional markers of ageing. For example, in germ-free conditions, the aging process is not associated with declining stress response genes and increasing innate immunity and many other conventional markers. However, some such as redox and metabolic process and mitochondrial function, are coupled. In effect, the microbiome is having a profound effect on the ageing process, suggesting trade-offs [66]. Tellingly, it seems that even large viruses have a kind of primitive immune system similar to prokaryotes [67]. This, therefore, indicates that ageing, immunity, and inflammation are all intimately related and have been so for billions of years.

Are there other biological clues as to the origins of immunity and, thus, more modern inflammation? Some may come from what was once called "junk DNA". Nowadays, it is realized that it has a very important function as transposons or mobile genetic elements (MGEs). In modern eukaryotes, it seems that as an organism ages, in a process associated with hypomethylation, its chromatin opens up, allowing the transcription of these MGEs. Critically, this seems to be associated with a gradual decrease in the activity of DNA repair mechanisms, which does not seem to occur in immortal organisms, such as hydra, or in germ line cells [68]. Certainly in modern eukaryotes, there is a very tight link between ageing and metabolism [69]—as would be predicted via the ability of the mitochondrion to control the epigenome [70]. Possible origins of this can be traced back to the CRISPR-cas system in prokaryotes, which is a primitive adaptive immune system that can help the prokaryote differentiate between a helpful gene or a nasty one, and where necessary, induce its death (similar systems exist in both Archaea and eubacteria) [71]. They, thus, may be helpful in environmental adaptation [72,73].

It may, therefore, be relevant that although mitochondrial stress can globally close chromatin, it also specifically opens up certain parts to allow the transcription of components involved in the unfolded protein response (UPR) and longevity [74]. It is, thus, interesting that extracellular prokaryotes still determine our lifespan. Quite apart from the obvious downside to infection, in the guts of modern animals, inflammation can accelerate the ageing of the whole organism by altering its microbiota [75]; the interaction of the microbiota with the immune system is very tightly controlled [76]. In short, clues to the origins of inflammation are found in our prokaryotic ancestors, and in the more obvious of their descendants, the mitochondrion. The emerging pivotal role that this organelle plays in inflammation and immunity [14] is, thus, highly suggestive. 


\subsection{The Role of the Mitochondrion in Cell Death in Modern Eukaryotes}

As indicated, it is likely that the death program is very old. In multicellular organisms, a well-known key player both in PCD and the ageing process is, of course, the mitochondrion [77]. In modern cells, mitochondria still display a variety of phenotypes, perhaps reminiscent of their ancestors, which undergo big changes in dynamics under stress-up to and including both fusion and mitophagy [78,79]. This mitochondrial dynamic is integral to the functioning of cells in the immune system, and is certainly one that pathogens have evolved to manipulate [80]. Insights into the role of this organelle in eukaryotes come from the observation that mitochondria control the epigenome through Krebs's cycle intermediates and various retrograde signaling mechanisms, which in turn, act to maintain mitochondrial integrity $[70,81-83]$. One very important aspect to mitochondrial functioning is the efficient conversion of high-energy electrons in food to energy held in the proton gradient; if this process is degraded, this can lead to both a reduction in mitochondrial membrane potential and an increase in ROS production. To reiterate a key point made before, the longer lived a species is, the more efficient its ETC, which results in a lower production of ROS, requiring less investment in anti-oxidant mechanisms and DNA repair [84].

Importantly, in most species, mitochondrial function does decline with age, and seems to be partly related to decreased autophagy and maintenance, as well as a Muller's ratchet mechanism amplifying damaging mitochondrial DNA mutations-and is matched by a down-regulation of genes involved in mitochondrial function, but an upregulation of innate immune genes [85]. Evidence suggests a definite increase in somatic mtDNA heteroplasmy with age [86]. In short, there is a relationship with declining mitochondrial function and increasing inflammation with age, which again signifies a redirection in electrons. This partly suggests that, as mitochondrial function degrades with age, it is recognized as a failing dissipative system, which activates the immune system.

However, although what happens in post-mitotic cells is important, it is what happens in germline cells that may be critical, as mitochondrial function is key in both the oocyte and the spermatozoon and selection for mitochondrial homeoplasmy in both the female and male- and both eggs and sperm deteriorate with age leading to reducing fertility and increased chances of less fit offspring [87-89]. Furthermore, to reiterate, inflammation, especially if chronic, can lead to infertility in both sexes $[42,90]$. The important point here is that inflammation controls the mitochondrion, for instance, amplifying inflammatory ROS signals by causing them to increase their production of ROS, as part of a normal anti-pathogenic response, which can eventually lead to resolution of the damage-but it obviously damages mitochondria in the process [13]. In effect, inflammatory signals can repurpose mitochondria, for instance, by providing ATP by glycolysis, resulting in mitochondrial membrane hyperpolarization coupled with succinate dehydrogenase activation to drive electrons towards ROS, rather than energy production [91]. However, critically, excessive mitochondrial ROS production can also drive apoptosis, so there is a fine balance between survive or death. Interestingly, some prokaryotes under stress can release diffusible factors that induce death in other cells in the colony by inhibiting their ETC and generating ROS; this releases DNA to produce protective biofilms. It has been proposed that this could represent an early version of what happens to mitochondria during apoptosis [62]. So, in one sense, inflammation can induce "die for the community" amongst eukaryotic cells, and the mechanism echoes that of what a bacterial mitochondrial ancestor could have done, and certainly appears to "upscale" to an entire multicellular organism. 


\subsection{Inflammation Rises with Age: Death via Hormetic Inflexibility}

The implications from this are that, although inflammation is clearly beneficial in the younger organism, as it ages, it becomes upregulated-especially if the organism becomes prematurely less "fit" - thus accelerating its demise. It is also likely that as an organism ages, its hormetic curve left shifts. Indeed, it does seem that the ageing trajectories of many organisms, including humans, are associated with a loss of physiological resilience and an exponential increase in mortality, as measured by something called the dynamic organism state indicator (DOSI). In effect, as an organism ages, its recovery time from a perturbation continuously increases until it cannot recover and dies; for humans, this suggests an absolute lifespan of between 120-150 years [92]. In addition, studies across multiple species looking at the "landscape of longevity", although indicating that lifespan can be modulated to some degree, suggest that degeneracy of body systems clearly continues when studied using Strehler-Mildvan degeneracy manifolds-and this method puts the absolute limit on human lifespan at about 138 years [93].

This matches pretty well what we actually see, with the oldest ever recorded human, Jeanne Calment, living to 122 years; most supercentenarians seem to have very low incidences of common diseases and display morbidity compression, with ill health only occurring near the end [94]. This of course makes centenarians fascinating studies of the successful ageing process. Of particular interest is that control of inflammation in both semi-supercentenarians, and their offspring, is a better predictor of successful ageing than telomeres-and is linked to better maintenance of cognition [95]. From a dissipative point of view, a certain amount of stress can, thus, be seen as perturbation and information, which induces a mild loss of order and, critically, a correction. This might even suggest that thinking, and the effort of thinking (processing information), could be hormetic-and, possibly, anti-inflammatory. This, of course, would reflect the informational cycle of Brillouin and the stabilization of a structure through information [96]. However, with "age", this ability inextricably decreases.

This, therefore, suggests that one of the simplest explanations of the ageing process is that the loss of homeostasis, which is largely heritable, and involves failing proteostasis (the ability to detect and remove the normal production of damaged components, preventing death by garbage, much like the inefficient removal of rubbish in cities which starts to hinder every other function, such as traffic flow). Although multiple pathways are involved in ageing, and it appears that some are conserved in many species, such as those involving mTOR (mammalian target of rapamycin), DNA repair, resistance to oxidative stress, or telomere length, there are obviously differences in how some species achieve longevity, which makes it difficult to pin down the precise genetic programs that determine human longevity [97]. However, a key element in all life are functional proteins, which have to be correctly folded; if not, this can not only directly reduce the efficiency of a particular pathway, but the incorrectly folded/damaged ones can become toxic to the entire system if they are not cleared, which is why protein homeostasis, or proteostasis, is so important in the ageing process [98]. Critically, chronic inflammation can lead to dysregulated proteostasis due to excessive ROS production, which in turn, can further drive the inflammatory process. This is well described to be part of the pathological process in neurodegeneration [99]. The link between ageing and inflammation is, thus, strong and is associated with telomere shortening and epigenetics [100,101]. It can, therefore, be said that the loss of homeostasis seems to be associated with a rise inflammation and a decreasing hormetic response, which seems to accelerate the ageing process and is associated with a gradual reduction in the ability to self-correct. 
This, therefore, partly suggests that a viable anti-ageing strategy uses hormesis to counteract "inflammaging". A good example is stimulating the production of mitokines by exercise from muscle to correct mitochondrial dysfunction. Certainly, for humans, this revolves around a healthy lifestyle. However, the kind of stress is important, as calorie excess can also drive inflammation, as can a lack of exercise, both of which induce metabolic dysfunction, indicating that these scenarios are outside of the normal evolutionary background [102]. Thus, although energy is key, too much can be detrimental, as indeed, can a lack of utilization-which seems to indicate that the systems for some forms of life have a goldilocks zone of dissipation optimized by evolution.

\subsection{Is Ageing Adaptive?}

As previously indicated, the adaptive senescence idea was first put forward by Weismann in 1889, and then expounded more than a 100 years later by Lewis and by Skulachev. Their theory highlights the importance of older individuals dying once they had passed their knowledge to the next generation to prevent excessive use of resources. They called this process "phenoptosis" [55]. It could be argued that if inflammation and hormesis are part of adaptive process driven by basic thermodynamics, then ageing could be viewed as adaptive to ensure the removal of less functional units and the generation of new ones.

However, it has often been said that ageing is mostly not adaptive. For instance, Hayflick suggested that although ageing could either be programmed (adaptive senescence), or a stochastic process that could lead to death due to a loss of molecular fidelity, he preferred the latter theory, which could be viewed as an increase in entropy and molecular disorder [103]. One of the counterarguments against adaptive senescence is that, despite a reasonable theoretical reason why older animals should be removed, for instance, to preserve resources for their younger and fitter offspring, there was no clear Darwin-inspired mathematical reason. However, some mathematical proofs have been developed involving natural selection in spatial systems that suggest that adaptive death, and thus, finite lifespans, have been selected for by evolution-ostensibly to prevent loss of the environment for future generations. In effect, programmed deaths result in long-term benefits to a lineage over many generations [54]. Certainly, some organisms, such as C. elegans, do seem to display a form of adaptive ageing and death to ensure colony fitness [104]. This might be supported in some animals, as genotoxic stress in the germ line, for instance, triggered by DNA damage can induce an organism-wide pre-conditioning response to resist stress via components of the immune system [45]. This is, of course, hormesis. Nevertheless, the bigger picture here is that removal of less functional units is perhaps traceable back to basic thermodynamic theories because they disrupt dissipation. There is another aspect to this, i.e., the effects of inflammation on behavior, which we will discuss in a later section.

It could, therefore, be suggested that ageing at the global level is indeed adaptive to ensure survival of life by removing less functional "units". How one views it may simply depend on the timeline and the scale. At the largest scale, inflammation can perhaps be seen as a mechanism to ensure that dissipative "negentropic" structures are maintained, ensuring that "life" continues to accelerate entropy by dissipating energy. Hormesis tests the system and is scale-invariant as it represents natural selection and survival of the fittest, but also the elimination of the weakest; this can be seen at the molecular, organelle, cellular, organism, and even species level. This, in turn, is a natural consequence of thermodynamics and perhaps the evolution of intelligence, as well as the development of awareness and technology, which of course accelerates the dissipative process. Modern humans use far more energy than their ancestors. The downside is that the technological species then understands 
its own mortality-Entropy's Dark Laughter [105]. Hence, inflammation can be viewed as an epiphenomena and as part of hormesis and the ability to adapt to stress; whether it is viewed as hormesis or inflammation just depends on scale, but is likely based on thermodynamics.

"Worn-out individuals are not only valueless to the species, but they are even harmful, for they take the place of those which are sound ... " August Weissmann, 1889

\section{Quantum Thermodynamic Underpinnings}

If the thermodynamic theories about self-organization are correct, the next question is, of course, how much of the quantum world has this embraced? Indeed, one of the key questions in biology has, for a long time, centered around whether life depends on amplified quantum effects beyond that expected from the usual scales expected at the temperatures that it operates at. Quantum mechanics is the best model we have to describe the atomic world, and with its discovery came the realization that it must also be applicable to biology, as eloquently discussed by Schrödinger [18].

It is thought that quantum effects were important in the origins of life [106-108], and continue to play a key role today [27]: much of this has been based on theory rather than observation. However, new data seems to have observed quantum-based electron tunnelling in biological systems [109]. By default, therefore, it is quite possible that significant quantum effects are important in life and underly both hormesis and inflammation, with redox and control of electron flow being critical. However, perhaps significantly, more recent theories are suggesting the concept of dissipative adaptation as a general thermodynamic mechanism that explains self-organization, where the most adapted are those with the highest work absorption and, thus, heat dispersal. This is now being extended to the quantum realm. In effect, a quantum thermodynamics of driven self-organization [26]. Using this, it now seems possible, at least using computer models, to bridge the gap from how an inanimate system becomes living as not only can it replicate, mutate, compete, and evolve, but can self-assemble [110].

However, there is also perhaps another observation that supports this-all life uncouples the ion gradients across its membranes, effectively creating a futile cycle and reducing the production of ATP, which at first sight, seems wasteful until one considers it is an active dissipating system. Thus, if quantum thermodynamics does explain adaptive self-organization in life, does it require enhanced quantum effects beyond the atomistic to function, or do they stay at the scales expected by conventional quantum mechanics? Herein lies the difficulty in defining what we mean by "quantum biology". Has biology utilized, and even enhanced, quantum effects beyond the conventional scales of time and distance? Is quantum biology simply an expression of a "warm" quantum world? In short, is biology simply what might be expected when thermodynamics and quantum mechanics are combined?

\subsection{From the Viewpoint of Thermal Vents-Tunnelling at the Beginning}

Although there is debate about whether the chemoautotrophic theory on the origins of life is stronger that the heterotrophic "organic soup" idea due to the nature of the freeenergy sources that drove the earliest anabolic reactions [49], there is good evidence that at least one form may have originated in thermal vents based on the acid-based energy gradient present in the immediate post-Hadean - key in this process were catalysts based on iron-sulfur centers and the evolution of molecules, such as the flavins, which enabled electron bifurcation to occur [111]. Critically, data now suggest that the modern successors to these, such as ferredoxin and flavin adenine dinucleotide (FAD), as well as many other proteins, are reliant on electron tunnelling to function [112,113]; tunnelling in mitochondria 
may, thus, be key in the way they work $[114,115]$. It also appears that proton tunnelling is also a central component of enzyme function [116]. Hence, it is possible that quantum effects were important in the origins of life $[107,117]$. Indeed, the confirmation of quantum effects in modern life, and the possibility that quantum criticality in macromolecules was actually selected for, supports this $[106,116,118,119]$.

It could be argued that one of the very first structures to emerge in a thermal vent was a form of ion channel that could extract free energy from the flow of ions [120]. It is entirely possible that compounds, such as FeS and NiS, which have semiconductor properties and are essential in the modern ETC, and could have been key in the evolution of life in thermal vents, acted as nuclei around proteins which evolved to harness quantum effects, such as tunnelling [121]. In effect, the antecedent to modern proteostasis was to maintain the function of these structures.

There is also perhaps another intriguing point that comes out of the thermal vent idea, and that is the importance of the temperature that life may have evolved at. Clearly, this is an inherent concept in thermodynamics, and certainly in biology, temperature plays a fundamental role in its functioning. For instance, the brain can be viewed as a dissipative out of equilibrium system; lowering its temperature can result in less excited states, and more order, but raising it has the opposite effect, being associated with clear biological outcomes (loss of cognition versus epilepsy) [122]. Intriguingly, lowering the temperature of mitochondria increases their production of ROS, while at the same time increasing lifespan [123]. However, for most complex species with an immune system, raising the body temperature is a key component in defending against pathogens, so is generally favorable; lowering temperature can reduce inflammation, but may compromise host defense [124]. Thus, there appears to be clear temperature sweet spot for optimum function for most species.

In terms of quantum biology, it was Fröhlich who suggested the idea that a thermally induced biological condensate could exist due to the formation of a lowest energy resonant coherent state [125]. This idea of thermally and light-driven resonance resulting in coherent states, in effect, quantum beating, is now thought to be key in enabling life temperature non-trivial quantum effects to exist, especially in light harvesting, but also, potentially, in relation to consciousness [126]. Thus, it could well be that, apart from the semi-conductor compounds mentioned above, which could enable tunnelling, the heat in a thermal vent could have been pivotal in generating a kind of Fröhlich condensate.

\subsection{Quantum-Based Sensing}

The implication from this is that biological systems can maintain quantum coherence that "senses" the environment. This, therefore, suggests that any change, e.g., in protein structure, would result in decoherence and could be a powerful signal as it would redirect quantum entities down different paths, thus driving life, adaptation, and death [24]. In effect, life relies on a classical Newtonian-quantum interface. Hence, in this respect, disruption of structure could, thus, be a key element in driving a signal to adapt as it would alter electron or proton flow, which would be an important adaptive signal. This of course suggests that proteostasis is essential to maintain the "quantum underground" in biology. It also brings into play the quantum mechanical definition of "dissipation", which is where the environment "dissipates" quantum states.

If we accept that redox stress is a key driver in inflammation and, thus, network disruption, then it could be viewed as simply an expression of a redox-based mechanism that drives evolution through adaption which could be reliant on quantum effects. At its simplest, the flow of electrons provides the energy for life, and if this flow does not occur 
correctly, it signals a problem; this can occur for many reasons, ranging from the lack of an electron donor (no food) to the lack of an electron acceptor (say, no oxygen), to disruption of the electron carrier proteins (due to miss-folding). In fact, it seems that through natural selection, the distances between redox centers have been selected to enable tunnelling [127].

It also might suggest that "quantum spin" may also be important, for instance, during free radical production. Certainly, photon-induced triplet states and a radical pair mechanism have long been discussed as a means of how birds may navigate by detection of weak magnetic fields [128], while weak magnetic fields seem to control stem cell growth via a possible mechanism involving spin and ROS production [129]. Very recently, data that magnetic fields can alter the autofluorescence of key biological molecules involved in redox, such as flavin adenine dinucleotide (FAD), which likely involves a spin-related free radical mechanism, have been produced [130]. Furthermore, it has also been proposed that the innate spin of some molecules, such as those containing $\mathrm{Fe}^{2+}$, because they generate their own magnetic fields, could actually protect against free radical production-for instance, in photosynthesis [131]. Overall, it does seem that biology generates its own electric fields, as well as photons, and seems to use significant quantum effects. It could well be reliant on quantum sensing using several different mechanisms that would, of course, also be key in homeostasis [132]. In effect, both spin and tunnelling, for instance, could play a key role in modulating redox.

\subsection{Uncoupling Equals Dissipation}

A key component of adaptive quantum-thermodynamic self-organizing principles is of course adaptive dissipation. In effect, areas of structure spontaneously arise that can enhance equilibrium of energy potentials. This refers to the constant use of free energy to keep the system "ticking over". For biology, this is defined by the constant recycling of ions across membranes, an apparently energy hungry process, which is perhaps best displayed by mitochondrial uncoupling; this is where the proton gradient is effectively "uncoupled" from the generation of ATP by allowing protons, as well as other ions, such as calcium, to flow back through the inner membrane. At first sight, this seems highly wasteful. However, it is a critical ROS controlling mechanism that also generates heat and is key in signaling. It is also perhaps highly suggestive that uncoupling can be anti-inflammatory-and it is perhaps no coincidence that many medicinal anti-inflammatory plant compounds can also uncouple, suggesting that modulation of dissipation is key in survival [9].

Although there are several ways that uncoupling can be achieved, one of the best studied relates to a group of uncoupling proteins (UCPs), which although some are involved in heat generation, many are not. For example, some are activated by fatty acids and can decrease ROS. Critically, as ROS generation is very dependent on the mitochondrial membrane potential $(\Delta \Psi)$ and as prokaryotes also display uncoupling $[133,134]$, this suggests this mechanism is ancient. It could well be that it ensures electron flow through the entire ETC, thus capturing more energy that would otherwise be lost in the formation of free radicals. Interestingly, decreasing the temperature also seems to decrease proton leak while potentially increasing ROS, but does improve respiratory efficiency-certainly in muscle mitochondria. Of particular importance in interpreting this is whether or not the mitochondria are phosphorylating; in state 4, when resting, the ETC would be more reduced and, thus, more likely to produce ROS [135]. It has also been shown that, in muscle, endurance training increases the mitochondrial efficiency, decreasing uncoupling, and is clearly associated with increased mitochondrial mass [136]. In contrast, inflammation suppresses it and is associated with a switch to glycolysis, a key component of the inflammatory response $[91,137,138]$. ROS is also a key growth proliferation signal [139]. Again, this can be viewed in another way: although it appears more efficient, it enables "work", i.e., movement, to be performed in another way. Exercise is just another means of dissipating an energy gradient; it could, in fact, be argued that, in the end, it actually accelerates entropy and dissipates an energy gradient more quickly. 
So this might suggest that inflammation and proliferation are similar, given that they rely on altered electron flow towards ROS and to the generation of metabolites to grow / rebuild, and would increase energy use. In effect, dissipation is achieved through growth rather than simply futile cycling, or perhaps, more movement. However, uncoupling is activated by ROS as a natural feedback system [133], suggesting that ROS generation is a very tightly controlled part of a homeostatic system. Hence, an animal that continues to move in its natural habitat, perhaps looking for food as it became calorie restricted, would use fatty acids for fuel, and would be expected to have increased mitochondrial mass, perhaps operating at optimal efficiency as the mitochondria would be operating in state 3 , so would not be highly reduced. If not moving, it would be cooler, with an enhanced respiratory efficiency; this might increase ROS, but this would be a powerful adaptive signal to maintain mitochondrial mass-especially if the signal was compartmentalized.

The key point is that mitochondria, and other membrane structures in cells, keep an electric potential across them, but there is always a constant leak that essentially creates a current that dissipates energy. This process continues even during calorie restriction, but the energy capture becomes more efficient. This process is, of course, essential in creating electric fields that have many functions, ranging from electrophoretic movement of metabolites, to ion signaling, environmental sensing, and, possibly, energy transfer and the control of coherence, as well as the generation of morphogenetic fields that define shape [132]. It is, thus, perhaps significant that it has now been calculated that proton tunnelling can occur through closed ion channels [140], potentially suggesting another mechanism to control dissipation.

\section{What Calorie Restriction May Tell Us}

As discussed, it would appear that (quantum) thermodynamics can provide a reasonable explanation of what life is, and why it arose-especially when large energy gradients existed. However, what happens when the energy becomes restricted? It might be predicted that individual structures would have less drive to replicate and, critically, less potential to become damaged-as long as they had some energy to dissipate. In short, they might "live" longer. Indeed, this is precisely what we seem to see with CR, which is when an organism finds itself having just enough energy to survive, but not as much as it wants. It could also be viewed as the flipside of inflammaging which represent the survival of the most efficient homeostatic system. In a way, although most biologists suggest that life is always trying to be efficient about using energy, it could be viewed that it is about selecting the most stable dissipating system. This may mean the removal of other less stable systems.

\subsection{Revisiting the Disposable Soma}

The thermodynamic theories discussed make a stark prediction about the removal of less stable systems. In this regard, the original "disposable soma" of ageing hypothesis, as developed by Kirkwood, suggests that throughout evolution, in an energy-restricted environment, putting energy into reproduction and growth, and protecting the germ line, is generally better than using it to maintain the soma, as it enables natural selection to work more quickly in response to environmental change. It was key that, for most of evolution, how long an individual lived was not determined by how fast it aged, but by environmental factors which lead to mortality. Hence, high levels of predation would tend to lead to shorter lifespans. The underlying principle here is that to prevent error catastrophe, most organisms must put energy into maintenance to ensure damaged components are removed and replaced, but this must be balanced with reproduction and growth. This has led to the lifespan of most species being genetically determined according to their environmental niche. In effect, ageing is related to the accuracy that organisms maintain macromolecular 
synthesis and is subject to natural selection. Thus, to enhance longevity, rates of growth and reproduction would need be reduced, which would be related to some fitness advantage that reduced predation and/or risk from environmental changes, such as starvation. Classic examples of this are flight, size, and intelligence. For example, bats, which are comparable in size to mice, live several times longer, whereas elephants, which are much bigger, live much longer than bats as they are also big and intelligent [141]. In a way, these latter examples show that being able to "outwit" the environment, in effect, taking on and using information to survive, ensures an individual can continue to dissipate for a longer. However, it also hints at a thermodynamic viewpoint on predation; it perhaps could enhance dissipation of energy gradients.

An update to the DS theory utilizes a systems biology approach, but emphasizes that although longevity is genetically programmed, it can be modulated in many species by multiple systems to ensure that the individual survives in times of hardship to ensure survival of the species. For example, by improving DNA repair programs, anti-oxidant systems and protein turnover. Perhaps the clearest example of this is CR that induces a reallocation of valuable resources to somatic maintenance to ensure the organism can survive long enough to breed when times are better. This approach has revealed clear relationships between replicative senescence, mitochondrial dysfunction, telomere erosion, and DNA damage. An important component of this is remove damaged (unfit) cells by apoptosis, or to arrest cell division by senescence [142]. To date, although there are still some competing theories on ageing, this resource allocation in response to environment change concept still holds true and has been applied to unicellular organisms [65]. This, of course, suggests that hormesis is describing this process, and that inflammation must, therefore, be related to it.

CR in humans certainly seems to suppress inflammation, but not cell-mediated immunity [143]. The overall effect is to greatly reduce oxidative stress and damage, enhancing some aspects of the immune system, such as cell-mediated immunity, but reducing ROS, which might compromise the ability to resist some pathogens [144-147]. It therefore seems that CR enhances mitochondrial efficiency and reduces inflammation, which is closely associated with the activation of sirtuins and control of redox [148]. In effect, the disposable soma seems to become less disposable when calories are restricted, and a key component is decreasing the potential for damage via oxidative stress. Thus, in a way, the disposable soma idea does support the underlying dissipation process when viewed from the viewpoint of energy restriction, meaning that evolution has resulted in a balance of responses (one puts everything into reproduction to ensure the generation of better adapted dissipating structures, while the other works by ensuring that the current structure improves its own maintenance). The latter seems to be, to some degree, associated with an ability to take on board and utilize information about the environment up to, and including, developing skills that avoid predation, such as flight and, quite possibly, size.

\subsection{CR Is Associated with Autophagy: Survival of Stable Dissipative Systems}

The thermodynamic principles underlying a far-from-equilibrium structure might also suggest that components might get reused. It has been suggested that somatic maintenance has not evolved as a mechanism in its own right; rather, CR slows ageing via a secondary effect brought about by increased autophagy and apoptosis to divert resources to support reproduction. Autophagy is an energy dependent process that recycles damaged cellular components. It has been suggested that, in the wild, the slowing of the ageing process would have little relevance as CR simply reduces fitness, and most animals would die from other causes long before it became important [149]. Certainly, there are arguments that it depends on the animals feeding habits; for example, it might be more important for animals 
exposed to irregular food supplies, but less for those with a constant food supply [150]. In fact, excessive CR is well known to inhibit reproduction (especially when reduced by $40 \%$ of what the animal would normally eat), but less severe levels may have less of an effect on fertility, and may even enhance reproduction, although this is dependent on the species. For instance, in male mice, mild CR seems to enhance markers of longevity, but have little effect on reproductive capacity [151].

The fact that both CR and exercise increase autophagy and increase functional longevity, while ageing is associated with decreased autophagy, seems to suggest that the removal of less functional mitochondria and other components of the cell results in improved cellular functioning and less chance of apoptosis. Mitophagy is anti-inflammatory as it removes mitochondria that produce high levels of ROS [152]. Data does indicate that CR enhances mitophagy [153]. In a way, autophagy, and mitophagy could also simply be viewed as forms of internal "predation" which ensure dissipation. Much as predators target weaker prey, autophagic systems target failing components.

Thus, conditions that require increased autophagy/mitophagy seem to slow the ageing process by reducing oxidative stress, which is associated with a kind of natural selection, both within the cell or malfunctioning whole cells, and, critically, reduced inflammation. If this is coupled to enhanced somatic maintenance, it would enable a larger network of cells to survive longer. So rather than saying that calorie restriction specifically increases functional longevity, it could be said that the ageing rate is slowed by reducing inflammatory tone, as electrons tend to make it all the way through the ETC, rather than being emitted earlier to create ROS. The underlying principle is very straight forward: with less electrons being available, the ETC is less likely to be reduced and generate a growth (inflammatory) signal. It therefore seems that CR controls the direction of electron flow, ensuring that it goes towards oxygen and reducing the signal to grow. From a thermodynamic network point of view, it could simply represent a realignment to the most stable and a potentially simpler dissipative system where the less stable systems are removed.

\section{Scaling Up: Inflammatory Effects on Behavior}

In the preceding sections, we touched upon the relationship between thermodynamics, quantum mechanics, life, its metabolism, and how inflammation and energy dictate the ageing process. However, there is another key factor to consider: adaptive intelligence and the ability to take on information to enhance robustness. The application of thermodynamics to a theory of the human mind, in particular, as an underpinning to psychology is certainly not new. For instance, the hierarchically mechanistic mind as a free-energy formulation of the human psyche. This suggests that depression is an evolved biobehavioral strategy to noxious social conditions. It is, however, complex, and the reader is referred to this text for a detailed explanation [154]. Although theories like this can provide an approach to explain some aspects of behavior, especially in some social scenarios, inflammation, per se, is still likely to be an important biological concept to help in understanding behaviors because of its relationship with bioenergetics.

It could be said that hormesis was not only essential at the beginning of life, but for the evolution of intelligence. The flip side is that inflammation, and/or a lack of hormesis, could have the opposite effect and result in the break-up of the network, which might reduce its ability to store information. Thus, the prediction could then be made, certainly in a higher organism, such as a human, that inflammation could reduce intelligence [96]. Indeed, one emerging observation is that a higher body mass index (BMI) often results in reduced cognitive abilities; for instance, it can be associated with episodic memory deficits in young adults [155]. The data also suggest that obesity is related to a lower intelligence quotient (IQ) and, overtime, a smaller hippocampal volume [156-160]. More recent data also show that increasing BMI can be associated with reduced cerebral blood flow, but can be offset by exercise [161]. Thus, inflammation may result in inevitable changes in behavior. 


\subsection{Cytokine-Induced Sickness Behaviour and Natural Selection}

Given the clear link between obesity and inflammation, it might suggest that some of the neural effects are linked to inflammation. In fact, it has been known for some time that inflammation can induce sickness behavior, including suppression of appetite. It was originally thought that cytokine-induced sickness behavior evolved to wholly benefit the animal itself, but evidence is now pointing to it actually being important in kin selection by isolating the infected animal [162]. In effect, inflammation may drive a behavioral change that would potentially remove the sick animal not only from its herd, limiting the spread of infection, but also its genes. Perhaps a clear example of this is the recent finding that certain pathogens can actually block the anorexic response to infection, ensuring that the animal survives for longer and, thus, disperses the pathogen more widely in its faeces [163]. In effect, inflammation, and its associated effects on cognition, could be acting as a tool for natural selection. Certainly, research continues to link the immune system and the brain; for instance, epigenetic signatures during ageing and neocortical thickness are tightly correlated with immune system genes [164]. Being less smart is perhaps a sign of a destabilizing dissipative network that requires recycling.

\subsection{The Brain Is Essential for Cognitive Buffering against the Environment}

In more complex organisms, the brain is essential as it enables adaptation through cognitive buffering, which is totally dependent on maintaining its structure. Excessive inflammation can clearly reduce its functioning and is thought to be involved in neurodegeneration [165]. For instance, activation of p53, which is part of a cellular stress detection and response system, induces microglia via inflammatory factors to strip synapses [166]. Furthermore, it does appear that the ageing process itself can be centrally controlled via the brain [167]. Not only does this suggest that a very ill animal could remove itself by dying, but if it does not die, the associated cytokine suppression of appetite would also be powerfully hormetic as it would reduce calorie intake, potentially suppressing excessive inflammation. In effect, a built-in homeostatic response based on thermodynamics.

Given the importance of autophagy in hormesis [168], and a recent study showing that the removal of senescent cells is key to slow down the ageing process [169], there is a finely tuned balance between inflammation and hormesis in controlling the rate of ageing related to energy. In this regard, data from studies on the role of the epigenetic clock in ageing suggest that autophagic function is reduced, and is associated with an accelerated ageing phenotype [170]. Interestingly, as new data shows that the epigenome can very reliably predict someone's age, there is also evidence that it can be reprogrammed to some extent, e.g., by parabiosis (the coupling of a younger animal's circulatory system with an older animal, which seems to rejuvenate the older animal). Which raises the question around whether these changes are representative of an underlying program, or do they reflect an accrual of damage with age? Some authors suggest it could be both-certainly, the increased activity of NF-kB could represent a response to stress [171]. This does suggest that the response to stress dictates both behavior and the ageing rate. The bottom line could well be that if the stress is overwhelming, perhaps indicative of a failing ETC system and an inability to maintain a quantum environment to say, tunnel electrons successfully, this results in recognizable behavior changes and the need to recycle a failing dissipating structure.

Potential inflammatory behavior effects are apparent. One of the main ones is the association of neuroinflammation with many psychological disorders, in particular, depression and environmental stress [172,173]. In fact, there does also seem to be a strong association with suicidal ideation and inflammation [174], and, interestingly, there is also one between obesity, depression, and suicide attempts [175] — and obesity is often associated with raised 
levels of inflammatory markers [176]. In effect, it seems that inflammation makes us depressed and more likely to take our own lives, but is more likely in overweight people. It is thus interesting that a recent trial found that having low fitness and a high BMI was associated with an altered perception of distance and perceived effort; a fit and thinner person sees a distant object as being closer and easier to obtain as opposed to someone who is overweight and unfit. In effect, people who weigh more, due to excess adipose tissue, will tend to choose less physically demanding activities [177]. It is, thus, likely that the metabolic syndrome and obesity, because of the associated inflammatory tone, would tend to suppress the will to do exercise [178]. In short, inflammation can control behavior and seems to be a higher order expression of a dissipating system's status.

\section{Summary: Putting the Biology in the Quantum-Redefining "Normal"}

In this paper, we explored the touch points between quantum mechanics, thermodynamics, hormesis, and inflammation-and, thus, ageing and death. Inflammation seems to be global system to detect, and if possible, repair dissipative systems, but if not, it seems to accelerate their demise to ensure others survive-though this is tightly linked into hormesis, which is an adaptive mechanism to stress. These "biological" concepts seem to fall squarely out of adaptive thermodynamics and self-organization of far-from-equilibrium systems that arise to dissipate energy potentials. However, does this understanding help us explore the role of quantum mechanics in biology, and perhaps, more importantly, apply it to our understanding of life, and potentially, improve our ability to survive via medicine?

At the present time, quantum mechanics is the best description we have of how the Universe operates. In some circumstances, certainly at cold temperatures, it seems that these effects can expand, both in time and space, across large clusters of molecules-however, this has always been the domain of purpose-built physics experiments, and many have thought that this is not the domain of "warm and wet" biology. Nevertheless, as nature constantly reminds and confounds us, evidence suggests that life may well be exhibiting some quantum effects that might not be expected at room temperature, such as expanded coherence [179]. Hence, modern-day scientists are developing new ways of searching for these "significant" or "amplified" or "non-trivial" quantum effects in biology, and certainly, there are significant experimental data to indicate that life could have found ways to embrace this - however, these ideas are not new and were suggested by the very earliest pioneers of quantum mechanics [25].

To date, however, the academic world is still cautious about the field of "quantum biology", despite the ever-increasing experimental findings giving proof that biology, indeed, uses "expanded" quantum principles beyond what might be expected at the temperatures it operates at. However, might this new understanding help us to find better ways to live longer and healthier lives? Would it mean that we may have to redefine what we think quantum mechanics is and rearrange our expectations? Could biology be the missing chunk of the puzzle in explaining our Universe and our search for a unified theory of everything? These questions are well beyond the scope of this current paper, but it might help to explain why the pursuit of quantum biology may have some benefits.

Author Contributions: A.V.W.N. conceived and wrote the manuscript; J.D.B. and G.W.G. contributed equally to critiquing the original drafts and the concepts therein, and approved the final manuscript. All authors have read and agreed to the published version of the manuscript.

Funding: The writing of this manuscript was supported by the Guy Foundation.

Conflicts of Interest: The authors declare no conflict of interest. 


\section{References}

1. Cone, J.B. Inflammation. Am. J. Surg 2001, 182, 558-562. [CrossRef]

2. Calabrese, E.J.; Baldwin, L.A. Chemical hormesis: Its historical foundations as a biological hypothesis. Toxicol. Pathol. 1999, 27, 195-216. [CrossRef] [PubMed]

3. Calabrese, E.J.; Kozumbo, W.J. The hormetic dose-response mechanism: Nrf2 activation. Pharmacol. Res. 2021, 167, 105526. [CrossRef] [PubMed]

4. $\quad$ Neafsey, P.J. Longevity hormesis. A review. Mech. Ageing Dev. 1990, 51, 1-31. [CrossRef]

5. Kenyon, C. The plasticity of aging: Insights from long-lived mutants. Cell 2005, 120, 449-460. [CrossRef]

6. Ristow, M.; Schmeisser, K. Mitohormesis: Promoting Health and Lifespan by Increased Levels of Reactive Oxygen Species (ROS). Dose Response 2014, 12, 288-341. [CrossRef] [PubMed]

7. Singh, C.K.; Chhabra, G.; Ndiaye, M.A.; Garcia-Peterson, L.M.; Mack, N.J.; Ahmad, N. The Role of Sirtuins in Antioxidant and Redox Signaling. Antioxid. Redox Signal. 2018, 28, 643-661. [CrossRef]

8. Gabande-Rodriguez, E.; Gomez de Las Heras, M.M.; Mittelbrunn, M. Control of Inflammation by Calorie Restriction Mimetics: On the Crossroad of Autophagy and Mitochondria. Cells 2019, 9, 82. [CrossRef]

9. Nunn, A.V.W.; Guy, G.W.; Botchway, S.W.; Bell, J.D. From sunscreens to medicines: Can a dissipation hypothesis explain the beneficial aspects of many plant compounds? Phytother. Res. 2020, 34, 1868-1888. [CrossRef] [PubMed]

10. Lane, N. A unifying view of ageing and disease: The double-agent theory. J. Theor. Biol. 2003, 225, 531-540. [CrossRef]

11. Salminen, A.; Huuskonen, J.; Ojala, J.; Kauppinen, A.; Kaarniranta, K.; Suuronen, T. Activation of innate immunity system during aging: NF-kB signaling is the molecular culprit of inflamm-aging. Ageing Res. Rev. 2008, 7, 83-105. [CrossRef] [PubMed]

12. Fulop, T.; Dupuis, G.; Baehl, S.; Le Page, A.; Bourgade, K.; Frost, E.; Witkowski, J.M.; Pawelec, G.; Larbi, A.; Cunnane, S. From inflamm-aging to immune-paralysis: A slippery slope during aging for immune-adaptation. Biogerontology 2016, 17, 147-157. [CrossRef] [PubMed]

13. West, A.P.; Shadel, G.S.; Ghosh, S. Mitochondria in innate immune responses. Nat. Rev. Immunol. 2011, 11, 389-402. [CrossRef]

14. Monlun, M.; Hyernard, C.; Blanco, P.; Lartigue, L.; Faustin, B. Mitochondria as Molecular Platforms Integrating Multiple Innate Immune Signalings. J. Mol. Biol. 2017, 429, 1-13. [CrossRef]

15. Barja, G. Towards a unified mechanistic theory of aging. Exp. Gerontol. 2019, 124, 110627. [CrossRef] [PubMed]

16. Toussaint, O.; Schneider, E.D. The thermodynamics and evolution of complexity in biological systems. Comp. Biochem. Physiol. A Mol. Integr. Physiol. 1998, 120, 3-9. [CrossRef]

17. Kondepudi, D.K.; De Bari, B.; Dixon, J.A. Dissipative Structures, Organisms and Evolution. Entropy 2020, 22, 1305. [CrossRef]

18. Schrodinger, E. What is Life? The Physical Aspect of the Living Cell; Cambridge University Press: Cambridge, UK, 1944.

19. Toussaint, O.; Remacle, J.; Dierick, J.F.; Pascal, T.; Frippiat, C.; Royer, V.; Chainiaux, F. Approach of evolutionary theories of ageing, stress, senescence-like phenotypes, calorie restriction and hormesis from the view point of far-from-equilibrium thermodynamics. Mech. Ageing Dev. 2002, 123, 937-946. [CrossRef]

20. Ilan, Y. Advanced Tailored Randomness: A Novel Approach for Improving the Efficacy of Biological Systems. J. Comput. Biol. 2020, 27, 20-29. [CrossRef]

21. Baffy, G.; Loscalzo, J. Complexity and network dynamics in physiological adaptation: An integrated view. Physiol. Behav. 2014, 131, 49-56. [CrossRef]

22. Terman, A.; Kurz, T.; Navratil, M.; Arriaga, E.A.; Brunk, U.T. Mitochondrial turnover and aging of long-lived postmitotic cells: The mitochondrial-lysosomal axis theory of aging. Antioxid. Redox Signal. 2010, 12, 503-535. [CrossRef] [PubMed]

23. Nunn, A.V.; Bell, J.D.; Guy, G.W. Lifestyle-induced metabolic inflexibility and accelerated ageing syndrome: Insulin resistance, friend or foe? Nutr. Metab. 2009, 6, 16. [CrossRef] [PubMed]

24. Nunn, A.V.; Guy, G.W.; Bell, J.D. The quantum mitochondrion and optimal health. Biochem. Soc. Trans. 2016, 44, 1101-1110. [CrossRef] [PubMed]

25. McFadden, J.; Al-Khalili, J. The origins of quantum biology. Proc. R. Soc. A 2018, 474. [CrossRef]

26. Valente, D.; Brito, F.; Werlang, T. Quantum dissipative adaptation. Commun. Phys. 2021, 4, 11. [CrossRef]

27. Marais, A.; Adams, B.; Ringsmuth, A.K.; Ferretti, M.; Gruber, J.M.; Hendrikx, R.; Schuld, M.; Smith, S.L.; Sinayskiy, I.; Kruger, T.P.J.; et al. The future of quantum biology. J. R. Soc. Interface 2018, 15, 640. [CrossRef]

28. Pulselli, R.M.; Simoncini, E.; Tiezzi, E. Self-organization in dissipative structures: A thermodynamic theory for the emergence of prebiotic cells and their epigenetic evolution. Biosystems 2009, 96, 237-241. [CrossRef] [PubMed]

29. Prigogine, I.; George, C. The second law as a selection principle: The microscopic theory of dissipative processes in quantum systems. Proc. Natl. Acad. Sci. USA 1983, 80, 4590-4594. [CrossRef] [PubMed]

30. England, J.L. Statistical physics of self-replication. J. Chem. Phys. 2013, 139, 121923. [CrossRef]

31. Szalay, M.S.; Kovacs, I.A.; Korcsmaros, T.; Bode, C.; Csermely, P. Stress-induced rearrangements of cellular networks: Consequences for protection and drug design. FEBS Lett. 2007, 581, 3675-3680. [CrossRef]

32. Gatenby, R.A.; Frieden, B.R. The critical roles of information and nonequilibrium thermodynamics in evolution of living systems. Bull. Math. Biol. 2013, 75, 589-601. [CrossRef] 
33. Lane, N. The Vital Question: Why is Life the Way It Is; Profile Books Ltd.: London, UK, 2015.

34. De la Fuente, I.M.; Martínez, L.; Carrasco-Pujante, J.; Fedetz, M.; López, J.I.; Malaina, I. Self-Organization and Information Processing: From Basic Enzymatic Activities to Complex Adaptive Cellular Behavior. Front. Genet. 2021, 12, 615. [CrossRef]

35. Goldbeter, A. Dissipative structures in biological systems: Bistability, oscillations, spatial patterns and waves. Philos. Trans. A Math. Phys. Eng. Sci. 2018, 376, 376. [CrossRef] [PubMed]

36. Smith, E.; Morowitz, H.J. The Origin and Nature of Life on Earth; Cambridge University Press: Cambridge, UK, 2016.

37. Levin, M. Bioelectric signaling: Reprogrammable circuits underlying embryogenesis, regeneration, and cancer. Cell 2021, 184, 1971-1989. [CrossRef]

38. Michel, D. Life is a self-organizing machine driven by the informational cycle of Brillouin. Orig. Life Evol. Biosph. 2013, 43, 137-150. [CrossRef] [PubMed]

39. Zhang, X.; Zhuchenko, O.; Kuspa, A.; Soldati, T. Social amoebae trap and kill bacteria by casting DNA nets. Nat. Commun. 2016, 7, 10938. [CrossRef]

40. Futo, M.; Opasic, L.; Koska, S.; Corak, N.; Siroki, T.; Ravikumar, V.; Thorsell, A.; Lenuzzi, M.; Kifer, D.; Domazet-Loso, M.; et al. Embryo-Like Features in Developing Bacillus subtilis Biofilms. Mol. Biol. Evol. 2021, 38, 31-47. [CrossRef]

41. Levin, M. The Computational Boundary of a "Self": Developmental Bioelectricity Drives Multicellularity and Scale-Free Cognition Front. Psychol. 2019, 10, 2688. [CrossRef]

42. Weiss, G.; Goldsmith, L.T.; Taylor, R.N.; Bellet, D.; Taylor, H.S. Inflammation in reproductive disorders. Reprod. Sci. 2009, 16, 216-229. [CrossRef]

43. Azenabor, A.; Ekun, A.O.; Akinloye, O. Impact of Inflammation on Male Reproductive Tract. J. Reprod. Infertil. 2015, 16, 123-129. [PubMed]

44. Lane, N. Mitonuclear match: Optimizing fitness and fertility over generations drives ageing within generations. Bioessays 2011, 33, 860-869. [CrossRef] [PubMed]

45. Poliezhaieva, T.; Ermolaeva, M.A. DNA damage in protective and adverse inflammatory responses: Friend of foe? Mech Ageing Dev. 2016, 11, 64. [CrossRef] [PubMed]

46. Kudryasheva, N.S.; Rozhko, T.V. Effect of low-dose ionizing radiation on luminous marine bacteria: Radiation hormesis and toxicity. J. Environ. Radioact. 2015, 142, 68-77. [CrossRef] [PubMed]

47. Camprubí, E.; de Leeuw, J.W.; House, C.H.; Raulin, F.; Russell, M.J.; Spang, A.; Tirumalai, M.R.; Westall, F. The Emergence of Life Space Sci. Rev. 2019, 215, 56. [CrossRef]

48. Say, R.F.; Fuchs, G. Fructose 1,6-bisphosphate aldolase/phosphatase may be an ancestral gluconeogenic enzyme. Nature 2010, 464, 1077-1081. [CrossRef] [PubMed]

49. Kaufmann, M. On the free energy that drove primordial anabolism. Int J. Mol. Sci 2009, 10, 1853-1871. [CrossRef] [PubMed]

50. Goda, N.; Kanai, M. Hypoxia-inducible factors and their roles in energy metabolism. Int. J. Hematol. 2012, 95, 457-463. [CrossRef] [PubMed]

51. Cortassa, S.; O’Rourke, B.; Aon, M.A. Redox-optimized ROS balance and the relationship between mitochondrial respiration and ROS. Biochim. Biophys. Acta 2014, 1837, 287-295. [CrossRef]

52. Sunil, B.; Talla, S.K.; Aswani, V.; Raghavendra, A.S. Optimization of photosynthesis by multiple metabolic pathways involving interorganelle interactions: Resource sharing and ROS maintenance as the bases. Photosynth. Res. 2013, 117, 61-71. [CrossRef]

53. Knupp, J.; Arvan, P.; Chang, A. Increased mitochondrial respiration promotes survival from endoplasmic reticulum stress. Cell Death Differ. 2018, 13, 1334. [CrossRef]

54. Werfel, J.; Ingber, D.E.; Bar-Yam, Y. Programed Death is Favored by Natural Selection in Spatial Systems. Phys. Rev. Lett. 2015, 114, 238103. [CrossRef] [PubMed]

55. Skulachev, V.P. Phenoptosis: Programmed death of an organism. Biochemistry 1999, 64, 1418-1426. [PubMed]

56. Fredriksson, K.; Tjader, I.; Keller, P.; Petrovic, N.; Ahlman, B.; Scheele, C.; Wernerman, J.; Timmons, J.A.; Rooyackers, O Dysregulation of mitochondrial dynamics and the muscle transcriptome in ICU patients suffering from sepsis induced multiple organ failure. PLoS ONE 2008, 3, e3686. [CrossRef]

57. Duque-Parra, J.E. Note on the origin and history of the term "apoptosis". Anat. Rec. B New Anat. 2005, 283, 2-4. [CrossRef]

58. Kerr, J.F.; Wyllie, A.H.; Currie, A.R. Apoptosis: A basic biological phenomenon with wide-ranging implications in tissue kinetics. Br. J. Cancer 1972, 26, 239-257. [CrossRef] [PubMed]

59. Allocati, N.; Masulli, M.; Di Ilio, C.; De Laurenzi, V. Die for the community: An overview of programmed cell death in bacteria. Cell Death Dis. 2015, 6, e1609. [CrossRef]

60. Wegener, G.; Krukenberg, V.; Riedel, D.; Tegetmeyer, H.E.; Boetius, A. Intercellular wiring enables electron transfer between methanotrophic archaea and bacteria. Nature 2015, 526, 587-590. [CrossRef]

61. Wang, J.; Bayles, K.W. Programmed cell death in plants: Lessons from bacteria? Trends Plant. Sci. 2013, 18, 133-139. [CrossRef] [PubMed]

62. Hazan, R.; Que, Y.A.; Maura, D.; Strobel, B.; Majcherczyk, P.A.; Hopper, L.R.; Wilbur, D.J.; Hreha, T.N.; Barquera, B.; Rahme, L.G Auto Poisoning of the Respiratory Chain by a Quorum-Sensing-Regulated Molecule Favors Biofilm Formation and Antibiotic Tolerance. Curr. Biol. 2016, 26, 195-206. [CrossRef] [PubMed] 
63. Giusti, C.; Tresse, E.; Luciani, M.F.; Golstein, P. Autophagic cell death: Analysis in Dictyostelium. Biochim. Biophys. Acta 2009, 1793, 1422-1431. [CrossRef]

64. Teuliere, J.; Bernard, C.; Bapteste, E. Interspecific interactions that affect ageing: Age-distorters manipulate host ageing to their own evolutionary benefits. Ageing Res. Rev. 2021, 11, 101375. [CrossRef]

65. Teuliere, J.; Bhattacharya, D.; Bapteste, E. Ancestral germen/soma distinction in microbes: Expanding the disposable soma theory of aging to all unicellular lineages. Ageing Res. Rev. 2020, 60, 101064. [CrossRef]

66. Shukla, A.K.; Johnson, K.; Giniger, E. Common features of aging fail to occur in Drosophilaraised without a bacterial microbiome. iScience 2021, 24, 703. [CrossRef] [PubMed]

67. Levasseur, A.; Bekliz, M.; Chabriere, E.; Pontarotti, P.; La Scola, B.; Raoult, D. MIMIVIRE is a defence system in mimivirus that confers resistance to virophage. Nature 2016, 531, 249-252. [CrossRef] [PubMed]

68. Sturm, A.; Ivics, Z.; Vellai, T. The mechanism of ageing: Primary role of transposable elements in genome disintegration. Cell Mol. Life Sci. 2015, 72, 1839-1847. [CrossRef] [PubMed]

69. Finkel, T. The metabolic regulation of aging. Nat. Med. 2015, 21, 1416-1423. [CrossRef]

70. Wallace, D.C.; Fan, W. Energetics, epigenetics, mitochondrial genetics. Mitochondrion 2010, 10, 12-31. [CrossRef] [PubMed]

71. Heussler, G.E.; Cady, K.C.; Koeppen, K.; Bhuju, S.; Stanton, B.A.; O’Toole, G.A. Clustered Regularly Interspaced Short Palindromic Repeat-Dependent, Biofilm-Specific Death of Pseudomonas aeruginosa Mediated by Increased Expression of Phage-Related Genes. MBio 2015, 6, e00129-15. [CrossRef] [PubMed]

72. Casacuberta, E.; Gonzalez, J. The impact of transposable elements in environmental adaptation. Mol. Ecol. 2013, 22, 1503-1517. [CrossRef]

73. Fontana, A. A hypothesis on the role of transposons. Biosystems 2010, 101, 187-193. [CrossRef]

74. Tian, Y.; Garcia, G.; Bian, Q.; Steffen, K.K.; Joe, L.; Wolff, S.; Meyer, B.J.; Dillin, A. Mitochondrial Stress Induces Chromatin Reorganization to Promote Longevity and UPR(mt). Cell 2016, 165, 1197-1208. [CrossRef]

75. Li, H.; He, J.; Jia, W. The influence of gut microbiota on drug metabolism and toxicity. Expert Opin. Drug Metab. Toxicol. 2016, 12, 31-40. [CrossRef]

76. Lee, Y.K.; Mazmanian, S.K. Has the microbiota played a critical role in the evolution of the adaptive immune system? Science 2010, 330, 1768-1773. [CrossRef]

77. Lane, N. Energetics and genetics across the prokaryote-eukaryote divide. Biol. Direct 2011, 6, 35. [CrossRef]

78. Wai, T.; Langer, T. Mitochondrial Dynamics and Metabolic Regulation. Trends Endocrinol. Metab. 2016, 27, 105-117. [CrossRef] [PubMed]

79. Archer, S.L. Mitochondrial dynamics-mitochondrial fission and fusion in human diseases. N. Engl. J. Med. 2013, 369, 2236-2251. [CrossRef]

80. Cervantes-Silva, M.P.; Cox, S.L.; Curtis, A.M. Alterations in mitochondrial morphology as a key driver of immunity and host defence. EMBO Rep. 2021, 22, e53086. [CrossRef] [PubMed]

81. Salminen, A.; Kaarniranta, K.; Hiltunen, M.; Kauppinen, A. Krebs cycle dysfunction shapes epigenetic landscape of chromatin: Novel insights into mitochondrial regulation of aging process. Cell Signal. 2014, 26, 1598-1603. [CrossRef]

82. Jazwinski, S.M. The retrograde response: When mitochondrial quality control is not enough. Biochim. Biophys. Acta 2013, 1833, 400-409. [CrossRef] [PubMed]

83. Esteves, P.; Pecqueur, C.; Alves-Guerra, M.C. UCP2 induces metabolic reprogramming to inhibit proliferation of cancer cells. Mol. Cell Oncol. 2015, 2, e975024. [CrossRef] [PubMed]

84. Barja, G. Updating the mitochondrial free radical theory of aging: An integrated view, key aspects, and confounding concepts. Antioxid. Redox Signal. 2013, 19, 1420-1445. [CrossRef] [PubMed]

85. Tower, J. Mitochondrial maintenance failure in aging and role of sexual dimorphism. Arch. Biochem. Biophys. 2015, 576, 17-31. [CrossRef]

86. Li, M.; Schroder, R.; Ni, S.; Madea, B.; Stoneking, M. Extensive tissue-related and allele-related mtDNA heteroplasmy suggests positive selection for somatic mutations. Proc. Natl. Acad. Sci. USA 2015, 112, 2491-2496. [CrossRef] [PubMed]

87. Eichenlaub-Ritter, U.; Wieczorek, M.; Luke, S.; Seidel, T. Age related changes in mitochondrial function and new approaches to study redox regulation in mammalian oocytes in response to age or maturation conditions. Mitochondrion 2011, 11, 783-796. [CrossRef] [PubMed]

88. Otten, A.B.; Smeets, H.J. Evolutionary defined role of the mitochondrial DNA in fertility, disease and ageing. Hum. Reprod. Update 2015, 21, 671-689. [CrossRef]

89. Van Blerkom, J. Mitochondrial function in the human oocyte and embryo and their role in developmental competence. Mitochondrion 2011, 11, 797-813. [CrossRef]

90. Hedger, M.P.; Meinhardt, A. Cytokines and the immune-testicular axis. J. Reprod. Immunol. 2003, 58, 1-26. [CrossRef]

91. Mills, E.L.; Kelly, B.; Logan, A.; Costa, A.S.; Varma, M.; Bryant, C.E.; Tourlomousis, P.; Dabritz, J.H.; Gottlieb, E.; Latorre, I.; et al. Succinate Dehydrogenase Supports Metabolic Repurposing of Mitochondria to Drive Inflammatory Macrophages. Cell 2016, 167, 457-470.e413. [CrossRef] 
92. Pyrkov, T.V.; Avchaciov, K.; Tarkhov, A.E.; Menshikov, L.I.; Gudkov, A.V.; Fedichev, P.O. Longitudinal analysis of blood markers reveals progressive loss of resilience and predicts human lifespan limit. Nat. Commun. 2021, 12, 2765. [CrossRef]

93. Podolskiy, D.I.; Avanesov, A.; Tyshkovskiy, A.; Porter, E.; Petrascheck, M.; Kaeberlein, M.; Gladyshev, V.N. The landscape of longevity across phylogeny. bioRxiv 2020, 17, 993. [CrossRef]

94. Motta, M.; Cardillo, E.; Vacante, M.; Malaguarnera, M. Supercentenarians: The oldest people in the world. Indian J. Med. Res. 2010, 131, 4-6. [PubMed]

95. Arai, Y.; Martin-Ruiz, C.M.; Takayama, M.; Abe, Y.; Takebayashi, T.; Koyasu, S.; Suematsu, M.; Hirose, N.; von Zglinicki, T. Inflammation, But Not Telomere Length, Predicts Successful Ageing at Extreme Old Age: A Longitudinal Study of Semisupercentenarians. EBioMedicine 2015, 2, 1549-1558. [CrossRef]

96. Nunn, A.V.; Guy, G.W.; Bell, J.D. The hormesis of thinking: A deeper quantum thermodynamic perspective. Int. J. Neurorehabilit. 2017, 4, 272. [CrossRef]

97. Treaster, S.; Karasik, D.; Harris, M.P. Footprints in the Sand: Deep Taxonomic Comparisons in Vertebrate Genomics to Unveil the Genetic Programs of Human Longevity. Front. Genet. 2021, 12, 73. [CrossRef] [PubMed]

98. Hipp, M.S.; Kasturi, P.; Hartl, F.U. The proteostasis network and its decline in ageing. Nat. Rev. Mol. Cell Biol. 2019, 20, 421-435. [CrossRef] [PubMed]

99. Sonninen, T.M.; Goldsteins, G.; Laham-Karam, N.; Koistinaho, J.; Lehtonen, S. Proteostasis Disturbances and Inflammation in Neurodegenerative Diseases. Cells 2020, 9, 2183. [CrossRef] [PubMed]

100. Irvin, M.R.; Aslibekyan, S.; Do, A.; Zhi, D.; Hidalgo, B.; Claas, S.A.; Srinivasasainagendra, V.; Horvath, S.; Tiwari, H.K.; Absher, D.M.; et al. Metabolic and inflammatory biomarkers are associated with epigenetic aging acceleration estimates in the GOLDN study. Clin. Epigenet. 2018, 10, 56. [CrossRef]

101. Zhang, J.; Rane, G.; Dai, X.; Shanmugam, M.K.; Arfuso, F.; Samy, R.P.; Lai, M.K.; Kappei, D.; Kumar, A.P.; Sethi, G. Ageing and the telomere connection: An intimate relationship with inflammation. Ageing Res. Rev. 2016, 25, 55-69. [CrossRef]

102. Santoro, A.; Martucci, M.; Conte, M.; Capri, M.; Franceschi, C.; Salvioli, S. Inflammaging, hormesis and the rationale for anti-aging strategies. Ageing Res. Rev. 2020, 64, 101142. [CrossRef]

103. Hayflick, L. Biological aging is no longer an unsolved problem. Ann. N. Y. Acad. Sci. 2007, 1100, 1-13. [CrossRef]

104. Galimov, E.R.; Gems, D. Shorter life and reduced fecundity can increase colony fitness in virtual Caenorhabditis elegans. Aging Cell 2020, 19, e13141. [CrossRef] [PubMed]

105. Nunn, A.V.; Guy, G.W.; Bell, J.D. The intelligence paradox; will ET get the metabolic syndrome? Lessons from and for Earth. Nutr Metab. 2014, 11, 34. [CrossRef] [PubMed]

106. Vattay, G.; Salahub, D.; Csabai, I.; Nassimi, A.; Kaufmann, S.A. Quantum Criticality at the Origin of Life. J. Phys. Conf. Ser 2015, 626, 012023. [CrossRef]

107. Trixler, F. Quantum Tunnelling to the Origin and Evolution of Life. Curr. Org. Chem. 2013, 17, 1758-1770. [CrossRef]

108. Trevors, J.T. Origin of microbial life: Nano- and molecular events, thermodynamics/entropy, quantum mechanisms and genetic instructions. J. Microbiol. Methods 2011, 84, 492-495. [CrossRef] [PubMed]

109. Xin, H.; Sim, W.J.; Namgung, B.; Choi, Y.; Li, B.; Lee, L.P. Quantum biological tunnel junction for electron transfer imaging in live cells. Nat. Commun. 2019, 10, 3245. [CrossRef] [PubMed]

110. Valente, D. Self-replication of a quantum artificial organism driven by single-photon pulses. Sci. Rep. 2021, 11, 16433. [CrossRef] [PubMed]

111. Sousa, F.L.; Thiergart, T.; Landan, G.; Nelson-Sathi, S.; Pereira, I.A.; Allen, J.F.; Lane, N.; Martin, W.F. Early bioenergetic evolution. Philos. Trans. R Soc. Lond. B Biol. Sci. 2013, 368, 20130088. [CrossRef]

112. Daizadeh, I.; Medvedev, D.M.; Stuchebrukhov, A.A. Electron transfer in ferredoxin: Are tunneling pathways evolutionarily conserved? Mol. Biol. Evol. 2002, 19, 406-415. [CrossRef]

113. Berstis, L.; Beckham, G.T.; Crowley, M.F. Electronic coupling through natural amino acids. J. Chem Phys. 2015, $143,225102$. [CrossRef]

114. Moser, C.C.; Farid, T.A.; Chobot, S.E.; Dutton, P.L. Electron tunneling chains of mitochondria. Biochim. Biophys. Acta 2006, 1757, 1096-1109. [CrossRef]

115. De Vries, S.; Dorner, K.; Strampraad, M.J.; Friedrich, T. Electron tunneling rates in respiratory complex I are tuned for efficient energy conversion. Angew. Chem. Int. Ed. Engl. 2015, 54, 2844-2848. [CrossRef]

116. Layfield, J.P.; Hammes-Schiffer, S. Hydrogen tunneling in enzymes and biomimetic models. Chem. Rev. 2014, 114, 3466-3494. [CrossRef]

117. Tamulis, A.; Grigalavicius, M. The emergence and evolution of life in a "fatty acid world" based on quantum mechanics. Orig. Life Evol. Biosph. 2011, 41, 51-71. [CrossRef]

118. Engel, G.S.; Calhoun, T.R.; Read, E.L.; Ahn, T.K.; Mancal, T.; Cheng, Y.C.; Blankenship, R.E.; Fleming, G.R. Evidence for wavelike energy transfer through quantum coherence in photosynthetic systems. Nature 2007, 446, 782-786. [CrossRef] [PubMed]

119. Hayashi, T.; Stuchebrukhov, A.A. Quantum electron tunneling in respiratory complex I. J. Phys. Chem. B 2011, 115, 5354-5364. [CrossRef] [PubMed]

120. Lane, N.; Martin, W.F. The origin of membrane bioenergetics. Cell 2012, 151, 1406-1416. [CrossRef] [PubMed] 
121. Nunn, A.V. The Quantum Beat of Life \& the Amplification of a Principle. What Biophotonics Can Tell Us about the Bioquantome. The Guy Foundation, 2019; pp. 28-38. Available online: https://www.theguyfoundation.org/publications/ (accessed on 8 November 2021).

122. Papo, D. Brain Temperature: What it means and what can it do for cognitive scientists. arXiv 2013, arXiv:1310.2906.

123. Ali, S.S.; Marcondes, M.C.; Bajova, H.; Dugan, L.L.; Conti, B. Metabolic depression and increased reactive oxygen species production by isolated mitochondria at moderately lower temperatures. J. Biol. Chem. 2010, 285, 32522-32528. [CrossRef]

124. Roberts, N.J., Jr. Temperature and host defense. Microbiol. Rev. 1979, 43, 241-259. [CrossRef]

125. Srobar, F. Frohlich systems in cellular physiology. Prague Med. Rep. 2012, 113, 95-104. [CrossRef]

126. Craddock, T.J.; Priel, A.; Tuszynski, J.A. Keeping time: Could quantum beating in microtubules be the basis for the neural synchrony related to consciousness? J. Integr. Neurosci. 2014, 13, 293-311. [CrossRef] [PubMed]

127. Moser, C.C.; Page, C.C.; Dutton, P.L. Darwin at the molecular scale: Selection and variance in electron tunnelling proteins including cytochrome c oxidase. Philos. Trans. R. Soc. Lond. B Biol. Sci. 2006, 361, 1295-1305. [CrossRef] [PubMed]

128. Wiltschko, R.; Niessner, C.; Wiltschko, W. The Magnetic Compass of Birds: The Role of Cryptochrome. Front. Physiol. 2021, 12, 667000. [CrossRef] [PubMed]

129. Van Huizen, A.V.; Morton, J.M.; Kinsey, L.J.; Von Kannon, D.G.; Saad, M.A.; Birkholz, T.R.; Czajka, J.M.; Cyrus, J.; Barnes, F.S.; Beane, W.S. Weak magnetic fields alter stem cell-mediated growth. Sci. Adv. 2019, 5, eaau7201. [CrossRef] [PubMed]

130. Ikeya, N.; Woodward, J.R. Cellular autofluorescence is magnetic field sensitive. Proc. Natl. Acad. Sci. USA 2021, 118, e2018043118. [CrossRef]

131. Marais, A.; Sinayskiy, I.; Petruccione, F.; van Grondelle, R. A quantum protective mechanism in photosynthesis. Sci. Rep. 2015, 5, 8720. [CrossRef] [PubMed]

132. Fels, D.; Cifra, M.; Scholkmann, F.E. Fields of the Cell; Fels, D., Cifra, M., Scholkmann, F., Eds.; Research Signpost: Trivandrum, India, 2015.

133. Mailloux, R.J.; Harper, M.E. Uncoupling proteins and the control of mitochondrial reactive oxygen species production. Free Radic. Biol. Med. 2011, 51, 1106-1115. [CrossRef]

134. Woyda-PLoSzczyca, A.M.; Jarmuszkiewicz, W. The conserved regulation of mitochondrial uncoupling proteins: From unicellular eukaryotes to mammals. Biochim. Biophys. Acta 2016, 1858, 21-33. [CrossRef]

135. Jarmuszkiewicz, W.; Woyda-PLoSzczyca, A.; Koziel, A.; Majerczak, J.; Zoladz, J.A. Temperature controls oxidative phosphorylation and reactive oxygen species production through uncoupling in rat skeletal muscle mitochondria. Free Radic. Biol. Med. 2015, 83, 12-20. [CrossRef]

136. Zoladz, J.A.; Koziel, A.; Woyda-PLoSzczyca, A.; Celichowski, J.; Jarmuszkiewicz, W. Endurance training increases the efficiency of rat skeletal muscle mitochondria. Pflugers Arch. 2016, 468, 1709-1724. [CrossRef] [PubMed]

137. Emre, Y.; Nubel, T. Uncoupling protein UCP2: When mitochondrial activity meets immunity. FEBS Lett. 2010, 584, 1437-1442. [CrossRef] [PubMed]

138. Du, R.H.; Wu, F.F.; Lu, M.; Shu, X.D.; Ding, J.H.; Wu, G.; Hu, G. Uncoupling protein 2 modulation of the NLRP3 inflammasome in astrocytes and its implications in depression. Redox Biol. 2016, 9, 178-187. [CrossRef] [PubMed]

139. Menon, S.G.; Goswami, P.C. A redox cycle within the cell cycle: Ring in the old with the new. Oncogene 2007, 26, 1101-1109. [CrossRef] [PubMed]

140. Ababneh, O.; Qaswal, A.B.; Alelaumi, A.; Khreesha, L.; Almomani, M.; Khrais, M.; Khrais, O.; Suleihat, A.; Mutleq, S.; Al-olaimat, Y.; et al. Proton Quantum Tunneling: Influence and Relevance to Acidosis-Induced Cardiac Arrhythmias/Cardiac Arrest. Pathophysiology 2021, 28, 400-436. [CrossRef]

141. Kirkwood, T.B.; Holliday, R. The evolution of ageing and longevity. Proc. R. Soc. Lond. B Biol. Sci. 1979, 205, 531-546.

142. Kirkwood, T.B. Systems biology of ageing and longevity. Philos. Trans. R. Soc. Lond. B Biol. Sci. 2011, 366, 64-70. [CrossRef] [PubMed]

143. Meydani, S.N.; Das, S.K.; Pieper, C.F.; Lewis, M.R.; Klein, S.; Dixit, V.D.; Gupta, A.K.; Villareal, D.T.; Bhapkar, M.; Huang, M.; et al. Long-term moderate calorie restriction inhibits inflammation without impairing cell-mediated immunity: A randomized controlled trial in non-obese humans. Aging 2016, 8, 1416-1431. [CrossRef]

144. Speakman, J.R.; Mitchell, S.E. Caloric restriction. Mol. Aspects Med. 2011, 32, 159-221. [CrossRef] [PubMed]

145. Picca, A.; Lezza, A.M. Regulation of mitochondrial biogenesis through TFAM-mitochondrial DNA interactions: Useful insights from aging and calorie restriction studies. Mitochondrion 2015, 25, 67-75. [CrossRef]

146. Bevilacqua, L.; Seifert, E.L.; Estey, C.; Gerrits, M.F.; Harper, M.E. Absence of uncoupling protein-3 leads to greater activation of an adenine nucleotide translocase-mediated proton conductance in skeletal muscle mitochondria from calorie restricted mice. Biochim. Biophys. Acta. 2010, 1797, 1389-1397. [CrossRef] [PubMed]

147. Asami, D.K.; McDonald, R.B.; Hagopian, K.; Horwitz, B.A.; Warman, D.; Hsiao, A.; Warden, C.; Ramsey, J.J. Effect of aging, caloric restriction, and uncoupling protein 3 (UCP3) on mitochondrial proton leak in mice. Exp. Gerontol. 2008, 43, 1069-1076. [CrossRef] [PubMed]

148. Imai, S.I.; Guarente, L. It takes two to tango: NAD+ and sirtuins in aging/longevity control. NPJ Aging Mech. Dis. 2016, 2, 16017. [CrossRef] [PubMed] 
149. Adler, M.I.; Bonduriansky, R. Why do the well-fed appear to die young? A new evolutionary hypothesis for the effect of dietary restriction on lifespan. Bioessays 2014, 36, 439-450. [CrossRef] [PubMed]

150. Holliday, R. Food, fertility and longevity. Biogerontology 2006, 7, 139-141. [CrossRef]

151. Rocha, J.S.; Bonkowski, M.S.; Masternak, M.M.; Franca, L.R.; Bartke, A. Effects of adult onset mild calorie restriction on weight of reproductive organs, plasma parameters and gene expression in male mice. Anim. Reprod. 2012, 9, 40-51.

152. Green, D.R.; Galluzzi, L.; Kroemer, G. Mitochondria and the autophagy-inflammation-cell death axis in organismal aging. Science 2011, 333, 1109-1112. [CrossRef]

153. Mehrabani, S.; Bagherniya, M.; Askari, G.; Read, M.I.; Sahebkar, A. The effect of fasting or calorie restriction on mitophagy induction: A literature review. J. Cachexia Sarcopenia Muscle 2020, 11, 1447-1458. [CrossRef]

154. Badcock, P.B.; Friston, K.J.; Ramstead, M.J.D.; Ploeger, A.; Hohwy, J. The hierarchically mechanistic mind: An evolutionary systems theory of the human brain, cognition, and behavior. Cogn. Affect Behav. Neurosci. 2019, 19, 1319-1351. [CrossRef]

155. Cheke, L.G.; Simons, J.S.; Clayton, N.S. Higher body mass index is associated with episodic memory deficits in young adults. Q. J. Exp. Psychol. 2016, 12, 163. [CrossRef]

156. Dahl, A.K.; Hassing, L.B.; Fransson, E.I.; Gatz, M.; Reynolds, C.A.; Pedersen, N.L. Body mass index across midlife and cognitive change in late life. Int. J. Obes. 2013, 37, 296-302. [CrossRef] [PubMed]

157. Smith, E.; Hay, P.; Campbell, L.; Trollor, J.N. A review of the association between obesity and cognitive function across the lifespan: Implications for novel approaches to prevention and treatment. Obes. Rev. 2011, 12, 740-755. [CrossRef] [PubMed]

158. Yates, K.F.; Sweat, V.; Yau, P.L.; Turchiano, M.M.; Convit, A. Impact of metabolic syndrome on cognition and brain: A selected review of the literature. Arterioscler. Thromb. Vasc. Biol. 2012, 32, 2060-2067. [CrossRef] [PubMed]

159. Yau, P.L.; Castro, M.G.; Tagani, A.; Tsui, W.H.; Convit, A. Obesity and metabolic syndrome and functional and structural brain impairments in adolescence. Pediatrics 2012, 130, e856-e864. [CrossRef] [PubMed]

160. Cherbuin, N.; Sargent-Cox, K.; Fraser, M.; Sachdev, P.; Anstey, K.J. Being overweight is associated with hippocampal atrophy: The PATH Through Life Study. Int. J. Obes. 2015, 39, 1509-1514. [CrossRef] [PubMed]

161. Knight, S.P.; Laird, E.; Williamson, W.; O'Connor, J.; Newman, L.; Carey, D.; De Looze, C.; Fagan, A.J.; Chappell, M.A.; Meaney, J.F.; et al. Obesity is associated with reduced cerebral blood flow-Modified by physical activity. Neurobiol. Aging 2021, 11, 8. [CrossRef]

162. Shakhar, K.; Shakhar, G. Why Do We Feel Sick When Infected-Can Altruism Play a Role? PLoS Biol. 2015, 13, e1002276. [CrossRef]

163. Rao, S.; Schieber, A.M.; O'Connor, C.P.; Leblanc, M.; Michel, D.; Ayres, J.S. Pathogen-Mediated Inhibition of Anorexia Promotes Host Survival and Transmission. Cell 2017, 168, 503-516.e512. [CrossRef] [PubMed]

164. Freytag, V.; Carrillo-Roa, T.; Milnik, A.; Samann, P.G.; Vukojevic, V.; Coynel, D.; Demougin, P.; Egli, T.; Gschwind, L.; Jessen, F.; et al. A peripheral epigenetic signature of immune system genes is linked to neocortical thickness and memory. Nat. Commun. 2017, 8, 15193. [CrossRef]

165. Doty, K.R.; Guillot-Sestier, M.V.; Town, T. The role of the immune system in neurodegenerative disorders: Adaptive or maladaptive? Brain Res. 2015, 1617, 155-173. [CrossRef]

166. Jebelli, J.; Hooper, C.; Pocock, J.M. Microglial p53 activation is detrimental to neuronal synapses during activation-induced inflammation: Implications for neurodegeneration. Neurosci. Lett. 2014, 583, 92-97. [CrossRef] [PubMed]

167. Zhang, X.; Zhang, G.; Zhang, H.; Karin, M.; Bai, H.; Cai, D. Hypothalamic IKKbeta/NF-kappaB and ER stress link overnutrition to energy imbalance and obesity. Cell 2008, 135, 61-73. [CrossRef] [PubMed]

168. Calabrese, V.; Cornelius, C.; Dinkova-Kostova, A.T.; Iavicoli, I.; Di Paola, R.; Koverech, A.; Cuzzocrea, S.; Rizzarelli, E.; Calabrese, E.J. Cellular stress responses, hormetic phytochemicals and vitagenes in aging and longevity. Biochim. Biophys. Acta 2012, 1822, 753-783. [CrossRef] [PubMed]

169. Baker, D.J.; Childs, B.G.; Durik, M.; Wijers, M.E.; Sieben, C.J.; Zhong, J.; Saltness, R.A.; Jeganathan, K.B.; Verzosa, G.C.; Pezeshki, A.; et al. Naturally occurring p16(Ink4a)-positive cells shorten healthy lifespan. Nature 2016, 530, 184-189. [CrossRef] [PubMed]

170. Pal, S.; Tyler, J.K. Epigenetics and aging. Sci. Adv. 2016, 2, e1600584. [CrossRef] [PubMed]

171. Ashapkin, V.V.; Kutueva, L.I.; Vanyushin, B.F. Aging Epigenetics: Accumulation of Errors or Realization of a Specific Program? Biochemistry 2015, 80, 1406-1417. [CrossRef] [PubMed]

172. Miller, A.H.; Maletic, V.; Raison, C.L. Inflammation and its discontents: The role of cytokines in the pathophysiology of major depression. Biol. Psychiatry 2009, 65, 732-741. [CrossRef] [PubMed]

173. Pasco, J.A.; Nicholson, G.C.; Williams, L.J.; Jacka, F.N.; Henry, M.J.; Kotowicz, M.A.; Schneider, H.G.; Leonard, B.E.; Berk, M. Association of high-sensitivity C-reactive protein with de novo major depression. Br. J. Psychiatry 2010, 197, 372-377. [CrossRef] [PubMed]

174. Steiner, J.; Bielau, H.; Brisch, R.; Danos, P.; Ullrich, O.; Mawrin, C.; Bernstein, H.G.; Bogerts, B. Immunological aspects in the neurobiology of suicide: Elevated microglial density in schizophrenia and depression is associated with suicide. J. Psychiatry Res. 2008, 42, 151-157. [CrossRef] [PubMed]

175. Carpenter, K.M.; Hasin, D.S.; Allison, D.B.; Faith, M.S. Relationships between obesity and DSM-IV major depressive disorder, suicide ideation, and suicide attempts: Results from a general population study. Am. J. Public Health 2000, 90, 251-257. [PubMed]

176. Hotamisligil, G.S. Inflammation and metabolic disorders. Nature 2006, 444, 860-867. [CrossRef] 
177. Sugovic, M.; Turk, P.; Witt, J.K. Perceived distance and obesity: It's what you weigh, not what you think. Acta Psychol. 2016, 165, 1-8. [CrossRef] [PubMed]

178. Nunn, A.V.; Guy, G.W.; Brodie, J.S.; Bell, J.D. Inflammatory modulation of exercise salience: Using hormesis to return to a healthy lifestyle. Nutr. Metab. 2010, 7, 87. [CrossRef] [PubMed]

179. Vattay, G.; Kauffman, S.; Niiranen, S. Quantum biology on the edge of quantum chaos. PLoS ONE 2014, 9, e89017. [CrossRef] 